\title{
Investigation on Control Strategies for a Single-Phase Photovoltaic Inverter Using PSCAD/EMTDC Software
}

Research Article

Cristiano Luiz Henz, Fabiano Perin Gasparin*

Post-Graduation Program in Mining, Metallurgical and Materials Engineering, Solar Energy Laboratory (LABSOL), Federal University of Rio Grande do Sul (UFRGS), Porto Alegre, Brazil

Received: May 23, 2021; Accepted: June 26, 2021

\begin{abstract}
In the last decades, electric power produced through photovoltaic conversion has been increasing because of the need to reduce fossil fuel burning. Recently, photovoltaic systems have become more competitive and their role in the renewable energies market share is steadily gaining in importance. Improvements in the power electronics employed in the DC/AC conversion are topics of interest in the quest for more efficient and eventually reduced-cost inverters. The goal of this paper is to perform an investigation of control strategies and propose a topology for a single-phase DC/AC converter for photovoltaic arrays using the simulation software Power System Computer Aided Design/ Electromagnetic Transient Design and Control (PSCAD/EMTDC). The circuit proposed in this paper employs an isolating transformer to a grid-connected photovoltaic inverter. The control strategy proposed uses the instantaneous reactive power theory ( $p-q$ theory) and phase-locked loop (PLL). The $p$-q theory uses two virtual axes in the Park Transformation, which provide to the control system a good dynamic response, accuracy, and decoupling between the control and power system. Computer simulations using the electromagnetic transient software PSCAD show the efficiency of the proposed strategy for a single-phase inverter. The control strategy and topology are quite simple and easy to implement in the future using a Digital Signal Processor (DSP). The results provide insights into new power electronics solutions, which can improve the efficiency and efficacy of the current available in DC/AC converters for photovoltaic systems.
\end{abstract}

Keywords: $D C / D C$ converters $• D C / A C$ converters $\bullet$ photovoltaic modules $\bullet$ pulse width modulation $\bullet$ solar energy

\section{Introduction}

In recent decades, the generation and consumption of electricity supplied by renewable energy systems have grown, and it is expected to continually expand. Solar and wind energy can be highlighted as non-polluting energy sources, recently demonstrating a significant increase in the electric sector (Hart, 2010; Monfared, et al., 2012; Sundar, et al., 2014; Xiao, 2017). As a non-polluting energy source, solar energy has stood out as being inexhaustible on the terrestrial time scale, currently becoming the most promising renewable energy (Massawe, 2013). The efficiency improvements in the solar radiation conversion to electricity, the attractive economic return, the low maintenance costs, a system lifetime up to 25 years or 30 years and the growing need for renewable energies make photovoltaic systems ideal for electricity generation in utility-scale or smaller distributed generation plants (Massawe, 2013; Pinho and Galdino, 2014; Xiao, 2017).

In parallel with the development and improvement of photovoltaic modules, the complementary components used for the generation/transformation of electricity have also been improved (Pinho and Galdino, 2014; Xiao, 2017). Among these, the power converters (i.e. DC/AC converters) play an essential role in the system. They are used to convert the direct voltage $\left(\mathrm{V}_{\mathrm{dc}}\right)$ from the photovoltaic module to alternating voltage $\left(\mathrm{V}_{\mathrm{ac}}\right)$ supplied directly to the electric grid or appliances in isolated systems. The so-called inverters or DC/AC converters are being constantly improved (Andish, et al., 2016; Jalilzadeh, et al. 2018). Their architectures have always 
sought better conversion efficiency, elimination of the harmonics generated in the DC to AC conversion, size reduction (and consequently a reduction of their final price) and an extension of its operating lifetime (Sundar, et al., 2014; Xiao, 2017; Guo et al., 2019; Andish, et al., 2016; Jalilzadeh, et al. 2018). Most renewable energy systems use DC/AC converters to transform the voltage from the photovoltaic modules $\left(\mathrm{V}_{\mathrm{pv}}\right)$ to a sinusoidal alternating voltage $\left(\mathrm{V}_{\text {grid }}\right)$, supplying energy for isolated loads (off-grid system) or directly connecting to the power grid (on-grid system) (Hart, 2010; Massawe, 2013; Sundar, Karthick and Rama Reddy, 2014; Xiao, 2017; Andish, et al., 2016; Jalilzadeh, et al. 2018). Figure 1 shows an example of an on-grid photovoltaic system usually used by several authors and manufacturers, and it was also adopted as a reference model in this article.

Power converters used in photovoltaic systems usually have two basic stages: DC/DC converter and DC/AC converter (Hart, 2010; Andish, et al., 2016; Jalilzadeh, et al. 2018). The first has the function of receiving the DC voltage from the photovoltaic modules and adapting it to the next stage (DC/AC converter) (Roomi, 2019). The $D C / A C$ converter will receive the appropriate photovoltaic voltage $\left(V_{p v}\right)$ from the $D C / D C$ converter and transform it into a scalable $A C$ voltage $\left(\mathrm{V}_{\text {grid }}\right)$ with both amplitude and angular displacement control, which is then delivered as AC power through a filter using an inductor (Hart, 2010; Xiao, 2017; Guo et al., 2019; Roomi, 2019; Andish, et al., 2016; Jalilzadeh, et al. 2018).

To perform the power exchange between the photovoltaic modules and the power grid in an efficient and controllable way, various power control strategies have been proposed in the literature: current hysteresis control $(\mathrm{CHC})$, voltage-oriented control (VOC), proportional-resonant (PR)-based control and constant P-Q control (CPQC) (Monfared, et al., 2012; Gajewski and Pienkowski, 2016; Simões and Farret, 2017).

In this paper, the control strategy used as a reference to establish the maximum power transfer between photovoltaic modules and the power grid is the CPQC. Figure 2 shows the block diagram of the control and power system proposed in this article.

In the CPQC strategy, electric current components from both active and reactive power are measured from the AC grid using a wattmeter. These components are compared with the signals from the Park transformation of the same AC power current $\left(I_{\text {grid }}\right)$ and the same AC power voltage $\left(\mathrm{V}_{\text {grid }}\right)$. Then they are coupled to a proportional-integral

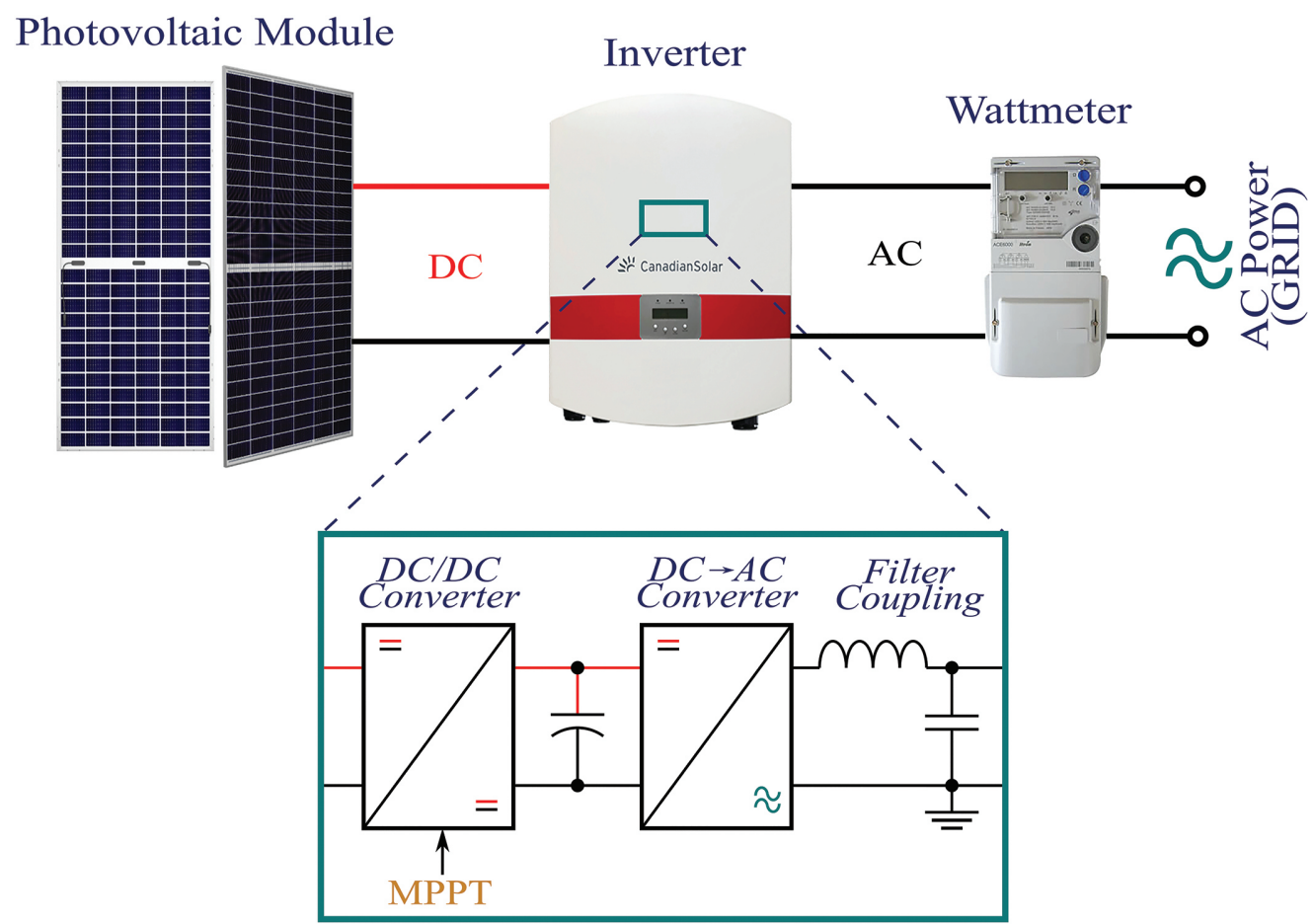

Fig. 1. Basic Scheme of an on-grid photovoltaic system. Source: adapted from Canadiansolar e Itron (Website - Canadiansolar (module), 2021; Website - Canadian (inverter), 2021; Website - Itron, 2021). 

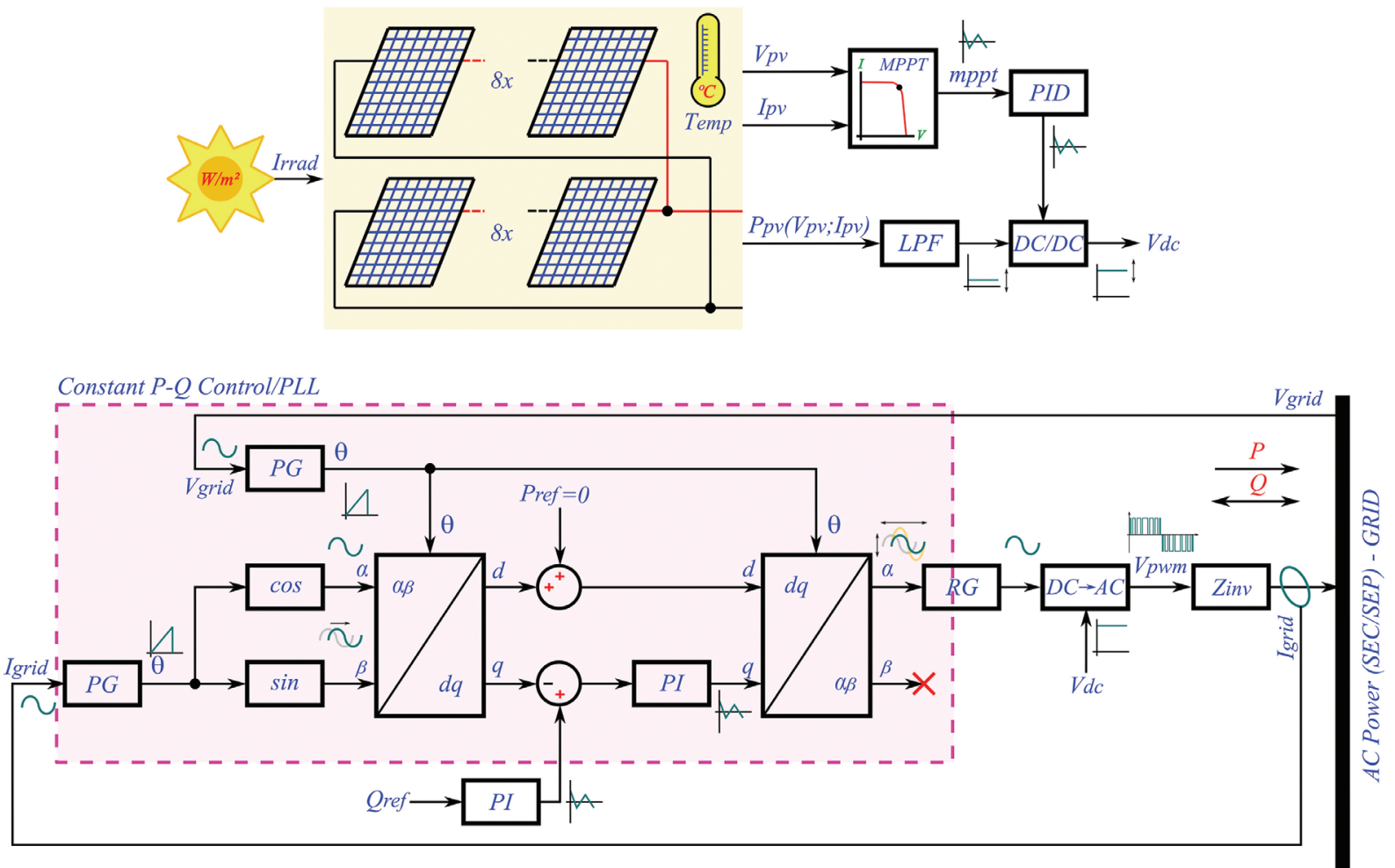

Fig. 2. Block diagram of control system and power system. DC/AC, direct current/alternating current; MPPT, maximum power point tracker; $\mathrm{PID}$, proportional-integral derivative; PG, phase generator; RG, reference generator; LPF, low-pass filter.

control $(\mathrm{PI})$ and the inverse Park transformation is performed, generating a sinusoidal signal with scalable amplitude and/or with forward or delay angular displacement for the Pulse Width Modulation (PWM) control of the DC/AC converter (Gajewski and Pienkowski, 2016).

This article presents the design and simulation results of a phase-locked loop (PLL) control system based on the CPQC for an on-grid single-phase inverter powered by photovoltaic modules. Together with the software PSCAD/ EMTDC Power Systems, developed by the Canadian company Manitoba Hydro International, was used to allow a practically real-time simulation with a dynamic interaction of parameters, such as irradiance and temperature on photovoltaic modules. In addition, it allows an excellent integration between the electrical grid and the power system electronics. The control strategy scheme CPQC was implemented and improved in the inverter design. Several solar irradiance conditions were simulated, providing insights into the efficacy, efficiency, precision and also keeping decoupling between the control system and the power system. The control strategy scheme allows easy practical implementation through a Digital Signal Processor (DSP) or even Field Programmable Gate Array (FPGA). Operational descriptions of each stage (both control and power system) and graphics from simulations obtained of PSCAD/EMTDC from the system confirm the theoretical foundations employed and the performance of the proposed inverter design.

\section{Methodology}

\subsection{Power stage}

Figure 3 shows the block structure of the proposed single-phase inverter power system, and afterward, each stage is explained.

Stage $\mathbf{A}$ - refers to photovoltaic modules that will feed the DC/DC converter in stage B. The schematic's electrical of stage A implemented in the PSCAD is shown in Figure 4. 


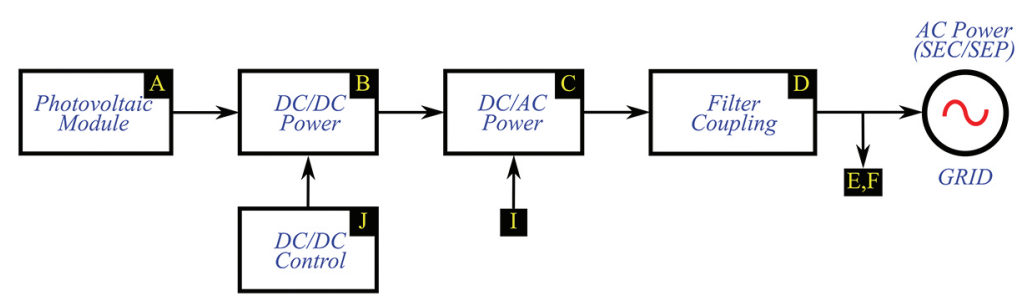

Fig. 3. Power stages of photovoltaic module, DC/DC converter, DC/AC converter, filter coupling and control system DC/DC.

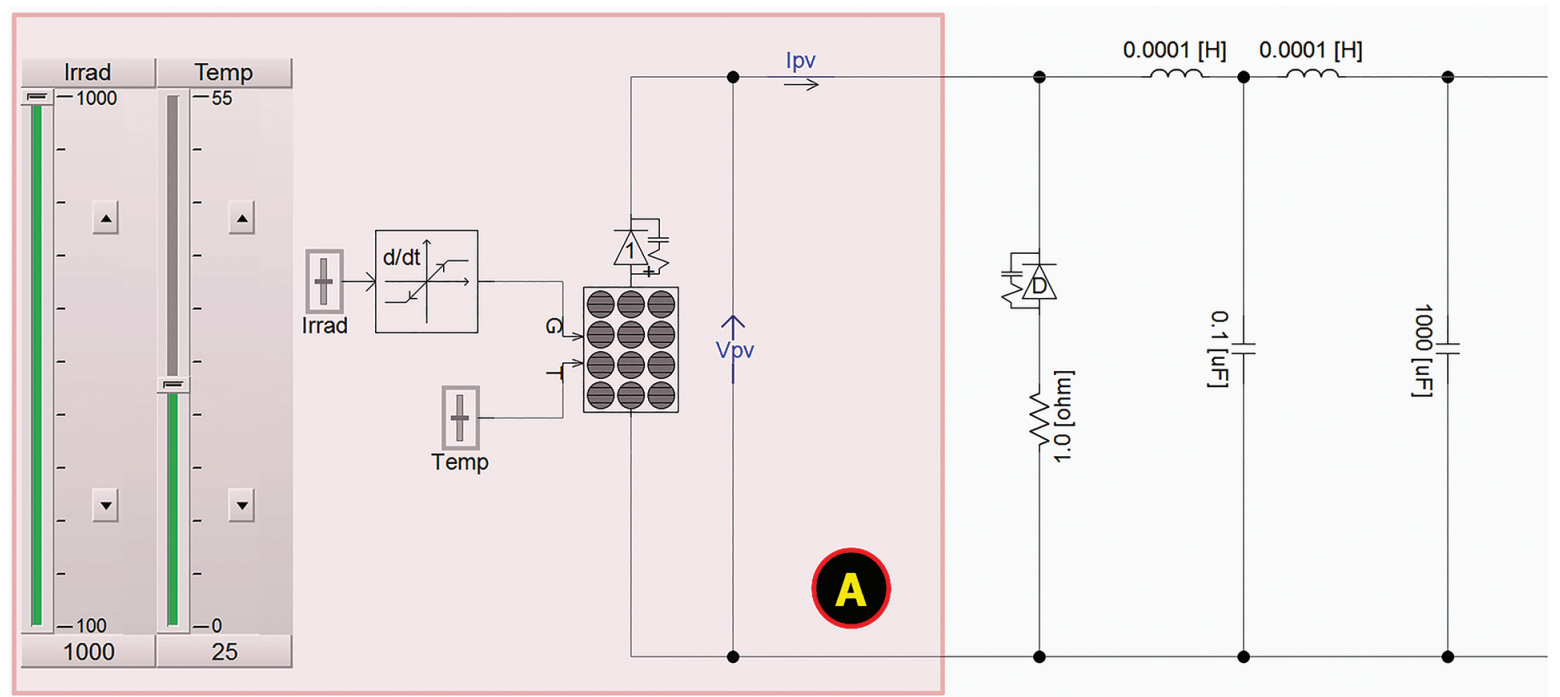

Fig. 4. Photovoltaic modules and two sliding potentiometers used to simulate the solar irradiance $\left(I_{\text {rad }}\right)$ and the temperature $\left(T_{\text {emp }}\right)$ in the PSCAD.

Two sliding potentiometers are used to simulate the solar irradiance $\left(I_{\text {rrad }}\right)$ in a range of $100-1,000 \mathrm{~W} / \mathrm{m}^{2}$ and the temperature $\left(T_{\text {emp }}\right)$ in a range of $5-50^{\circ} \mathrm{C}$ on the photovoltaic modules. The photovoltaic module has a non-linear characteristic current versus voltage (I-V) curve, where each curve changes according to the parameters of temperature and solar irradiance on the photovoltaic module (Xiao, 2017). Each I-V curve has a maximum power point $\left(\mathrm{P}_{\mathrm{mpp}}\right)$ wherein occurs the maximum power transfer between the photovoltaic module and the load (Massawe, 2013; Pinho and Galdino, 2014; Xiao, 2017). The location of the maximum power point in the I-V curve changes according to the variation of temperature and solar irradiance. To demonstrate the control strategy applied to the proposed inverter topology in this article, solar irradiations of $1,000 \mathrm{~W} / \mathrm{m}^{2}$, $800 \mathrm{~W} / \mathrm{m}^{2}, 600 \mathrm{~W} / \mathrm{m}^{2}, 400 \mathrm{~W} / \mathrm{m}^{2}, 200 \mathrm{~W} / \mathrm{m}^{2}$ and $100 \mathrm{~W} / \mathrm{m}^{2}$ were used for a fixed temperature of $25{ }^{\circ} \mathrm{C}$. In addition, all voltages and signals are considered at steady-state and the initial charging of capacitors was not evaluated. Table 1 shows all parameters used for the configuration of the photovoltaic module in the PSCAD/EMTDC software.

The configurations presented in Table 1 provide short-circuit current $\left(\mathrm{I}_{\mathrm{sc}}\right)$ of $30 \mathrm{~A}$ and open-circuit voltage $\left(V_{o c}\right)$ of $400 \mathrm{Vdc}$ for solar irradiance of $1,000 \mathrm{~W} / \mathrm{m}^{2}$. These are the limiting values of current and voltage that can be obtained from the photovoltaic array, although no power is obtained at these points (Massawe, 2013; Xiao, 2017). Figure 5 shows the I-V curves and Figure 6 shows the power versus voltage (P-V) curves simulated without the coupled power system of the photovoltaic module for solar irradiance of $1,000 \mathrm{~W} / \mathrm{m}^{2}, 800 \mathrm{~W} / \mathrm{m}^{2}$, $600 \mathrm{~W} / \mathrm{m}^{2}, 400 \mathrm{~W} / \mathrm{m}^{2}, 200 \mathrm{~W} / \mathrm{m}^{2}$ and $100 \mathrm{~W} / \mathrm{m}^{2}$ for a fixed temperature of $25^{\circ} \mathrm{C}$ obtained through the PSCAD software.

There are several direct and indirect techniques for tracking the maximum power point $\left(\mathrm{P}_{\mathrm{mpp}}\right)$ of a photovoltaic module/array I-V curve (Dousoky, et al., 2013; Eltawil and Zhao, 2013; Massawe, 2013; Chettibi and Mellit, 2014; Rezk and Eltamaly, 2015; Xiao, 2017; Kwasny and Zieliński, 2021). In this article, the incremental conductance technique was chosen. This technique is widely used due to its high precision for determining the maximum power point, allowing good adaptability and fast response to variations of irradiance and temperature on the photovoltaic 
Table 1. Parameters used in PSCAD/EMTDC software for the photovoltaic module in stage A

\begin{tabular}{|c|c|c|c|c|c|}
\hline \multicolumn{2}{|l|}{$\mathrm{PV}$ array parameters } & \multicolumn{2}{|l|}{ PV cell parameters } & \multicolumn{2}{|l|}{ Monitoring } \\
\hline PV array name (optional) & Pvarray1 & PV array name (optional) & Pvarray1 & PV array name (optional) & Pvarray 1 \\
\hline $\begin{array}{l}\text { N. of modules connected in } \\
\text { series/array }\end{array}$ & 8 & Effective area/cell $\left(m^{2}\right)$ & 0.01 & Photo current/module (A) & - \\
\hline $\begin{array}{l}N^{\circ} \text {. of module strings in parallel/ } \\
\text { array }\end{array}$ & 2 & Series resistance/cell $(\Omega)$ & 0.0026 & Internal diode current/module (A) & - \\
\hline $\begin{array}{l}\text { No. of cells connected in series/ } \\
\text { module }\end{array}$ & 72 & Shunt resistance/cell $(\Omega)$ & 1,000 & Internal diode voltage/module (V) & - \\
\hline $\begin{array}{l}\text { No. of cell strings in parallell } \\
\text { module }\end{array}$ & 1 & Diode ideality factor & 1.130 & Internal power loss/module (W) & - \\
\hline Reference irradiation $\left(\mathrm{W} / \mathrm{m}^{2}\right)$ & 1,000 & Band gap energy (eV) & 1.103 & Output power/module (W) & - \\
\hline \multirow[t]{3}{*}{ Reference cell temperature $\left({ }^{\circ} \mathrm{C}\right)$} & 25 & $\begin{array}{l}\text { Saturation current at reference } \\
\text { conditions/cell (kA) }\end{array}$ & $1 e-12$ & $P V$ array output current $(A)$ & - \\
\hline & & $\begin{array}{l}\text { Short-circuit current at reference } \\
\text { conditions/cell }(\mathrm{k} A)\end{array}$ & 0.015 & PV array output voltage (V) & - \\
\hline & & $\begin{array}{l}\text { Temperature coefficient of photo } \\
\text { current }(A / K)\end{array}$ & 0.0017 & & \\
\hline
\end{tabular}

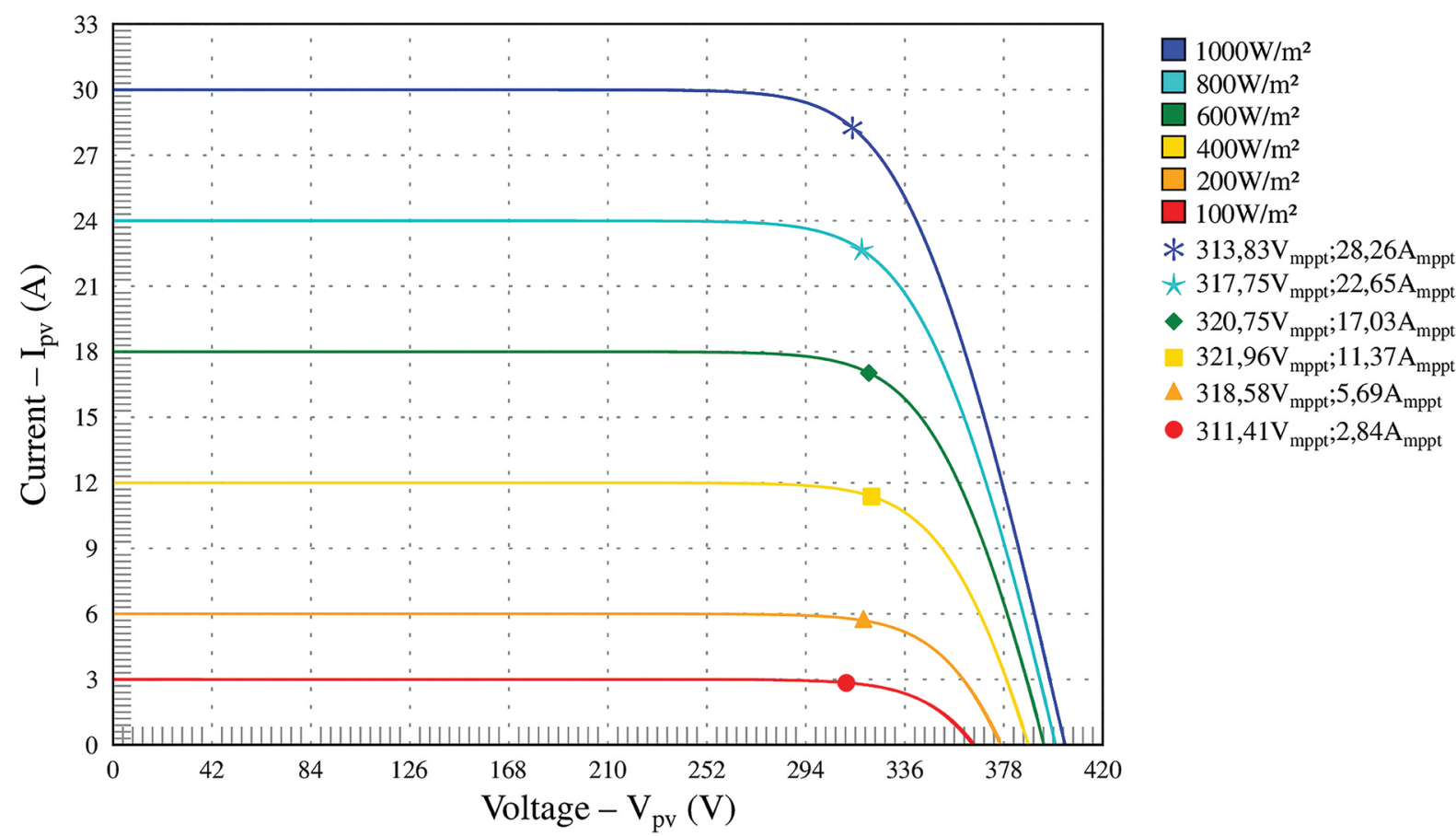

Fig. 5. $I_{p v}$ versus $V_{p v}$ response curves for solar irradiations of $1,000 \mathrm{~W} / \mathrm{m}^{2}, 800 \mathrm{~W} / \mathrm{m}^{2}, 600 \mathrm{~W} / \mathrm{m}^{2}, 400 \mathrm{~W} / \mathrm{m}^{2}, 200 \mathrm{~W} / \mathrm{m}^{2}$ and $100 \mathrm{~W} / \mathrm{m}^{2}$ at $25^{\circ} \mathrm{C}$.

array (Dousoky, et al., 2013; Eltawil and Zhao, 2013; Massawe, 2013; Chettibi and Mellit, 2014; Sundar, et al., 2014; Rezk and Eltamaly, 2015; Xiao, 2017). This technique uses the slope characteristics of the photovoltaic power curve to sweep the polarisation over the maximum power point $\left(\mathrm{P}_{\mathrm{mpp}}\right)$ and, for this, compares the instantaneous conductance $\frac{I_{p v}}{V_{p v}}$ with the incremental conductance $\frac{\Delta I_{p v}}{\Delta V_{p v}}$, according to the algorithm presented in Eq. (1), which is illustrated in Figure 7 (Dousoky, et al., 2013; Eltawil and Zhao, 2013; Massawe, 2013; Chettibi and Mellit, 2014; Sundar, et al., 2014; Rezk and Eltamaly, 2015; Xiao, 2017). 


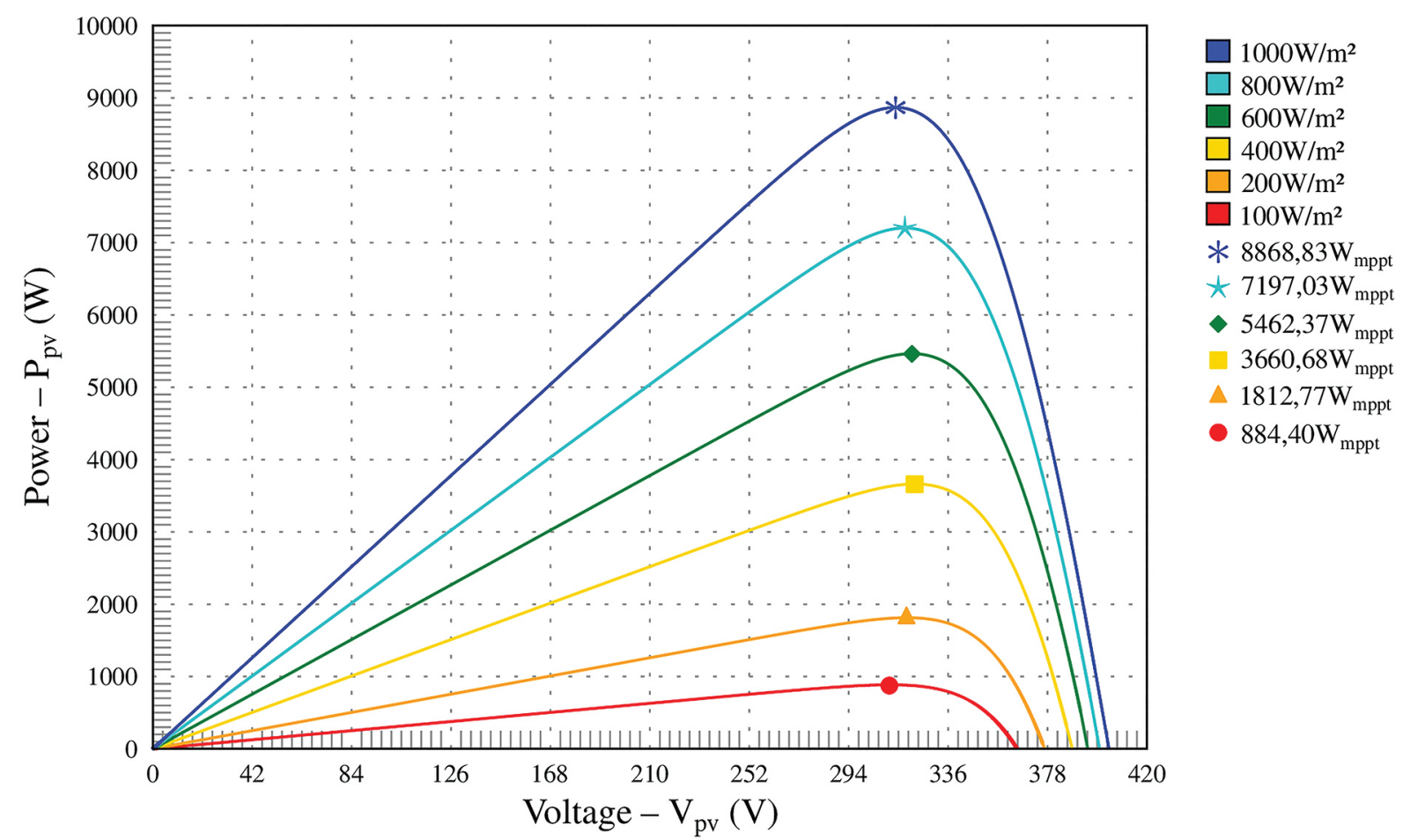

Fig. 6. $P_{p v}$ versus $V_{p v}$ response curves for solar irradiations of $1,000 \mathrm{~W} / \mathrm{m}^{2}, 800 \mathrm{~W} / \mathrm{m}^{2}, 600 \mathrm{~W} / \mathrm{m}^{2}, 400 \mathrm{~W} / \mathrm{m}^{2}, 200 \mathrm{~W} / \mathrm{m}^{2}$ and $100 \mathrm{~W} / \mathrm{m}^{2}$ at $25^{\circ} \mathrm{C}$.

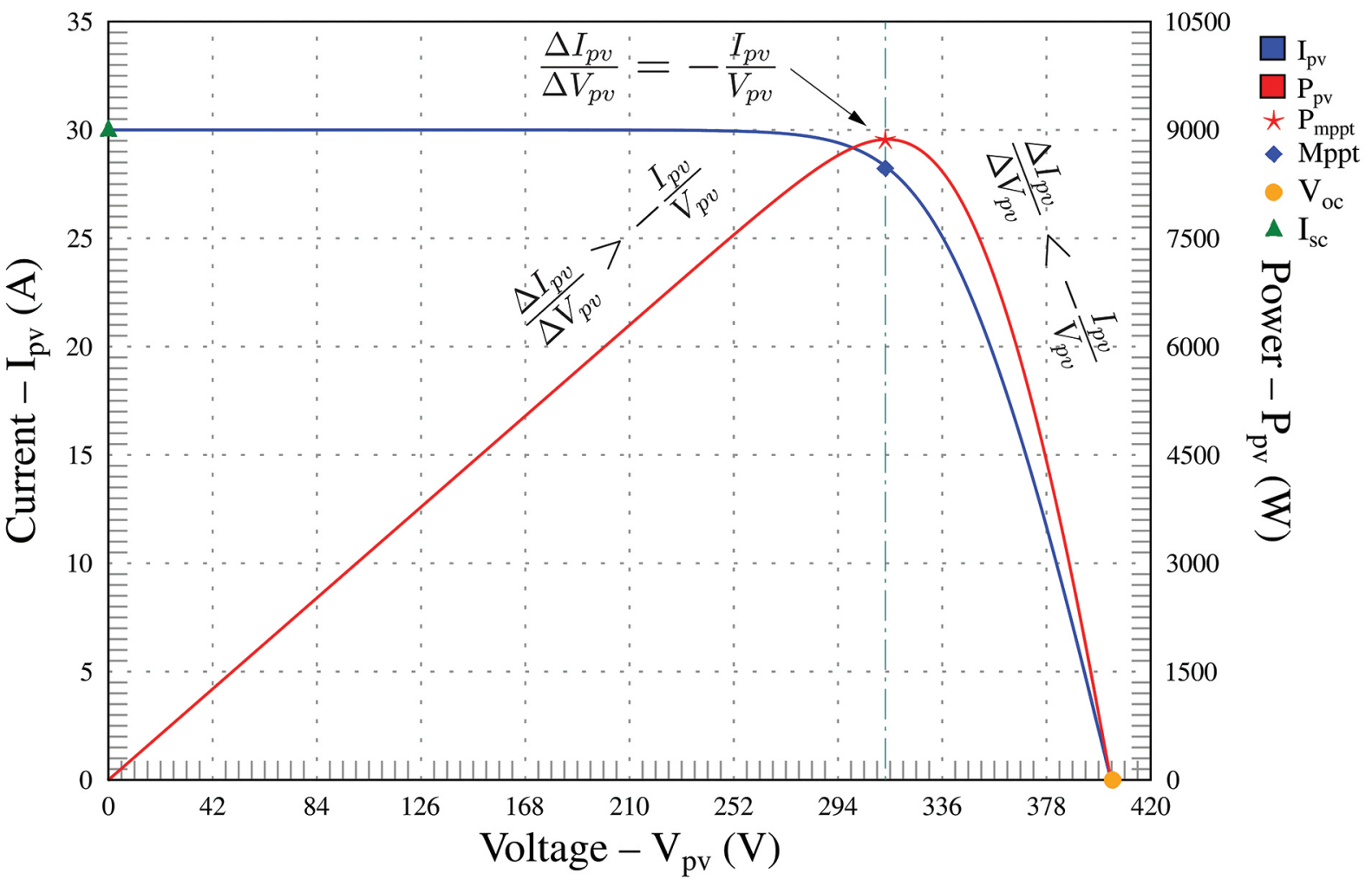

Fig. 7. MPPT using incremental conductance technique. MPPT, maximum power point tracker. 


$$
\left\{\begin{array}{l}
\frac{\Delta I_{p v}}{\Delta V_{p v}}=-\frac{I_{p v}}{V_{p v}} ;\left(\frac{\Delta P_{p v}}{\Delta V_{p v}}=0\right) \rightarrow \text { on maximum power point } \\
\frac{\Delta I_{p v}}{\Delta V_{p v}}>-\frac{I_{p v}}{V_{p v}} ;\left(\frac{\Delta P_{p v}}{\Delta V_{p v}}>0\right) \rightarrow \text { left maximum power point } \\
\frac{\Delta I_{p v}}{\Delta V_{p v}}<-\frac{I_{p v}}{V_{p v}}\left(\frac{\Delta P_{p v}}{\Delta V_{p v}}<0\right) \rightarrow \text { right maximum power point }
\end{array}\right.
$$

where $\Delta I_{p v}$ is the variation of the photovoltaic current; $\Delta V_{p v}$ is the variation of the photovoltaic voltage; $I_{p v}$ is the photovoltaic current; and $V_{p v}$ is the photovoltaic voltage.

According to Eq. (1), the maximum power point tracker (mppt) signal in Figure 2 will have zero value when the voltage on the I-V curve is located on the same vertical axis of the maximum power point of the power curve $\left(P_{\text {mpp }}\right)$. If the voltage on the I-V curve is located on the left of the axis of the maximum power point of the power curve $\left(P_{\text {mpp }}\right)$, the mppt signal (Figure 2) will have a positive value. And finally, when the voltage on the I-V curve is located on the right side of the axis of the maximum power point of the power curve $\left(P_{m p p}\right)$, the mppt signal (Figure 2$)$ will have a negative value (Dousoky, et al., 2013; Johnson, 2013; Xiao, 2017).

Stage $\mathbf{J}$ - The PSCAD/EMTDC software has a specific control block called MPPT that is based on the algorithm of the incremental conductance technique, producing a reference signal (mppt) that will be compared to a triangular signal. The electrical schematic of stage $\mathrm{J}$ implemented in the PSCAD/EMTDC is depicted in Figure 8.

The signal generated by the comparison between the mppt signal and the triangular signal has a square waveform with variable duty-cycle according to the level of the mppt signal. In this way, two signals (PP1 and PP2) will be generated through a flip-flop type $D$ to switching the transistors of the DC/DC converter of stage $B$.

The mppt signal level will vary depending on the temperature and solar irradiance conditions. In this way, it will vary the duty-cycle and the output power provided by the DC/DC converter. The configuration of the DC/DC converter control circuit has the advantage of having high efficiency in tracking and adapting to the maximum power point and allowing it to be easily implemented (Massawe, 2013; Chettibi and Mellit, 2014; Xiao, 2017; Roomi, 2019).

Stage B - in this stage, the voltage received by the photovoltaic module is adequate to supply the transistors of the DC/AC converter at stage C. The electrical schematic of stage B implemented in the PSCAD is depicted in Figure 9.

The technique used for the DC/DC converter is a full-bridge converter. This conversion technique uses a highfrequency switching transformer, thus allowing a high isolation efficiency between primary and secondary and making the transformer small when compared to conventional transformers that do not use transistor switching (Hart, 2010; Massawe, 2013; Xiao, 2017). In addition to these advantages, the switching transformer can perform

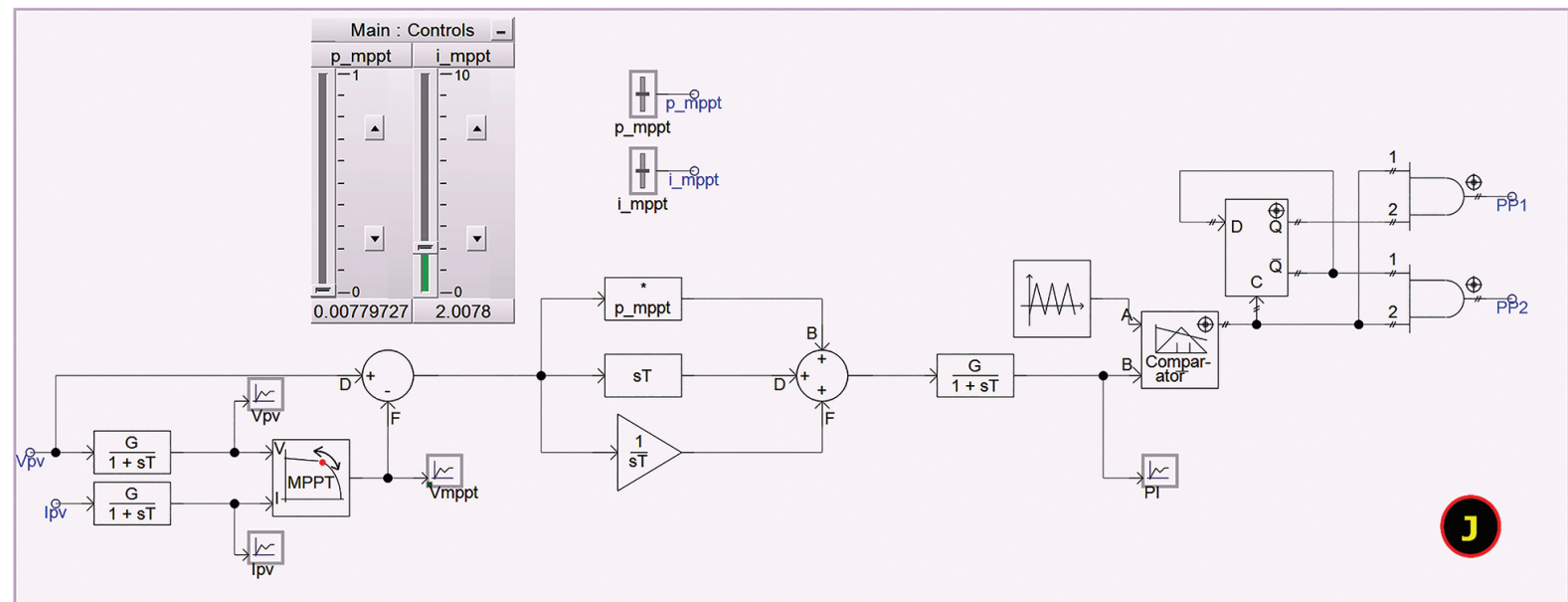

Fig. 8. MPPT with incremental conductance technique implemented in the PSCAD. MPPT, maximum power point tracker. 


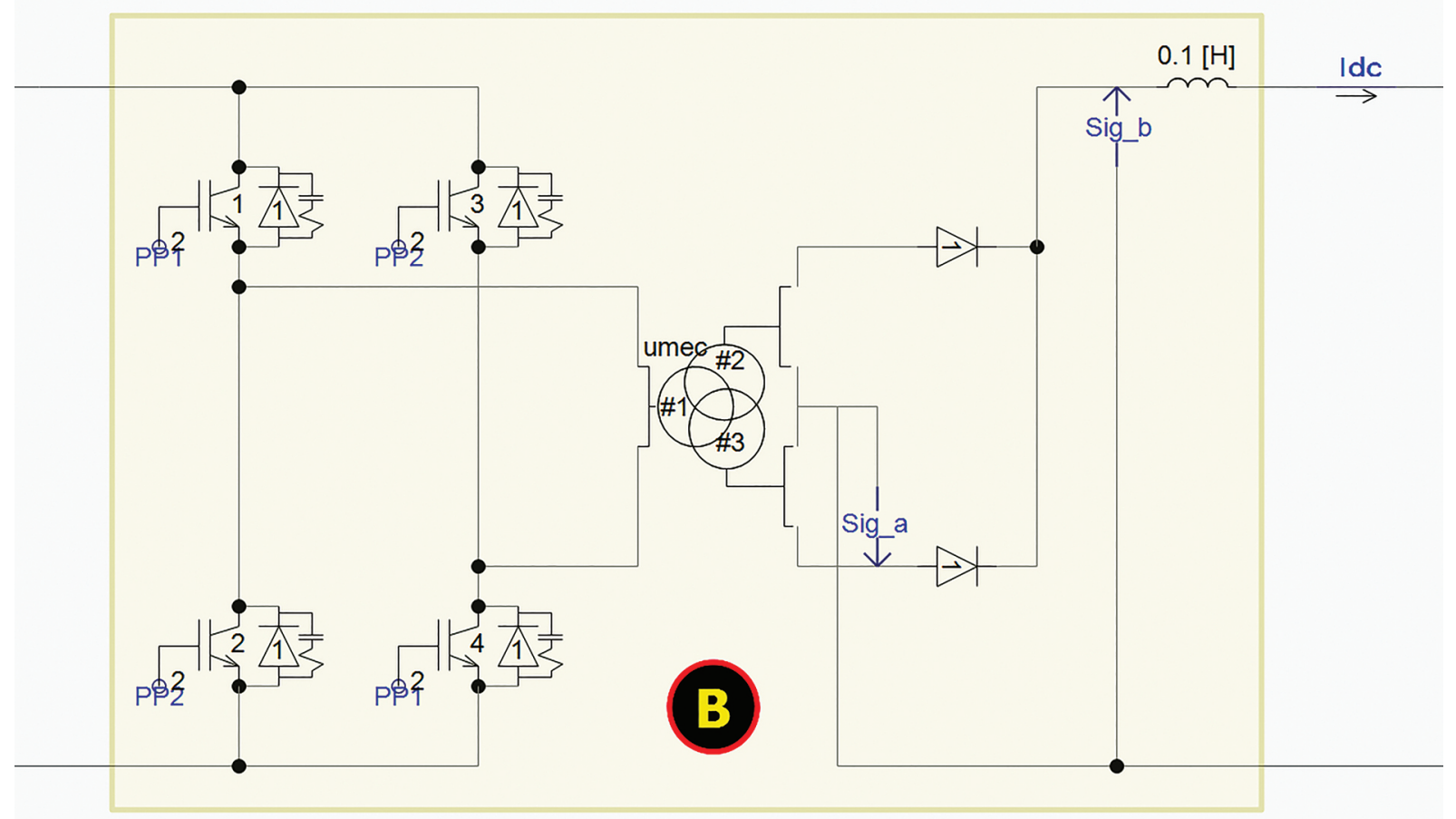

Fig. 9. Power $D C / D C$ full-bridge converter implemented in the PSCAD.

several transformation ratios, which allows it to raise or reduce the secondary voltage to a large range according to the duty-cycle switching of transistors in the primary (Hart, 2010; Sundar, et al., 2014; Xiao, 2017).

The voltage supplied by the full-bridge converter is given by Eq. (2) (Hart, 2010; Xiao, 2017).

$$
V_{o}=2 V_{s}\left(\frac{N_{s}}{V_{p}}\right) D
$$

where $V_{o}$ is the Output voltage; $V_{s}$ is the transformer secondary voltage; $N_{s}$ is the number of turns of the secondary coil; $V_{p}$ is the transformer primary voltage; and $D$ is the duty-cycle.

Through PP1 and PP2 signals coming from the control circuit (stage J), the power circuit of stage B can control the output voltage level $\left(\mathrm{V}_{\mathrm{dc}}\right)$ by regulating the duty-cycle, and consequently, control the power delivered to stage $\mathrm{C}$. The power delivered is the maximum power from the photovoltaic module.

Stage C, I - this stage converts the regulated DC voltage $\left(V_{d c}\right)$ from stage $B$ to single-phase modulated $A C$ voltage $\left(V_{\text {grid }}\right)$, providing it to the coupling stage D (Hart, 2010). The electrical schematics of stages $C$ and I implemented in the PSCAD are represented in Figures 10 and 11.

In specialised and specific literature, several configuration structures are presented for active power components (Barbi, 2008). The selection of the ideal structure for the inverter depends on several factors concerning the devices used, such as cost, power, thermal efforts, ease of acquisition, size etc. (Barbi, 2008).

The structure of the DC/AC converter used in stage $C$ is the full-bridge structure, since this structure is the one which is most frequently used, recommended for relatively high power $(>1 \mathrm{~kW})$, and is having as interesting characteristics the minimisation of transformer stresses, inductors and transistors including the versatility that the topology offers (Barbi, 2008; Massawe, 2013; Xiao, 2017). Figure 12 shows the complete bridge structure adopted.

$\mathrm{T}_{1}, \mathrm{~T}_{2}, \mathrm{~T}_{3}$ and $\mathrm{T}_{4}$ transistors are triggered according to a chosen modulation strategy. Many modulation strategies are proposed in the literature, among them: single pulse modulation, width modulation by multiple and equal pulses, modulation by optimised pulse width modulation (optimised PWM) and sinusoidal pulse width modulation (SPWM) (Barbi, 2008; Massawe, 2013; Xiao, 2017). The control strategy of transistor pulses selected was the unipolar 


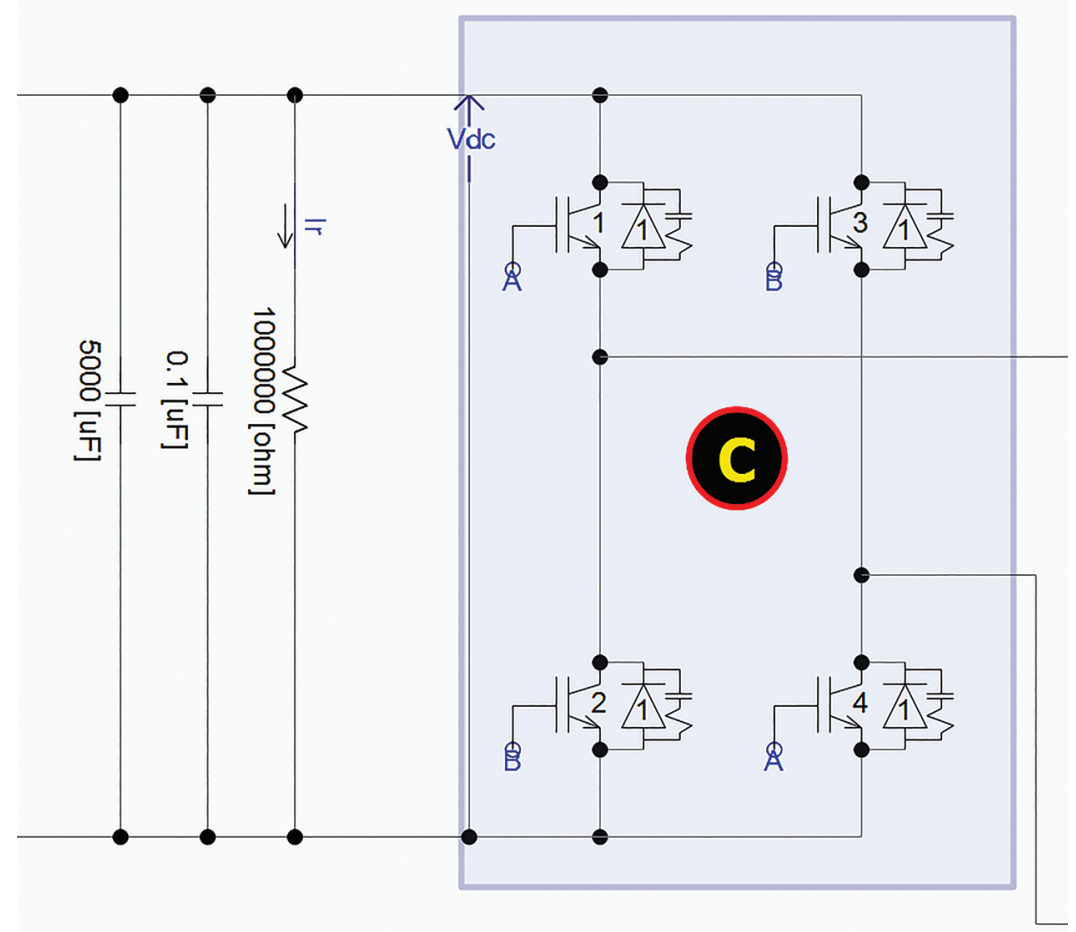

Fig. 10. Power $D C / A C$ full-bridge converter implemented in the PSCAD.

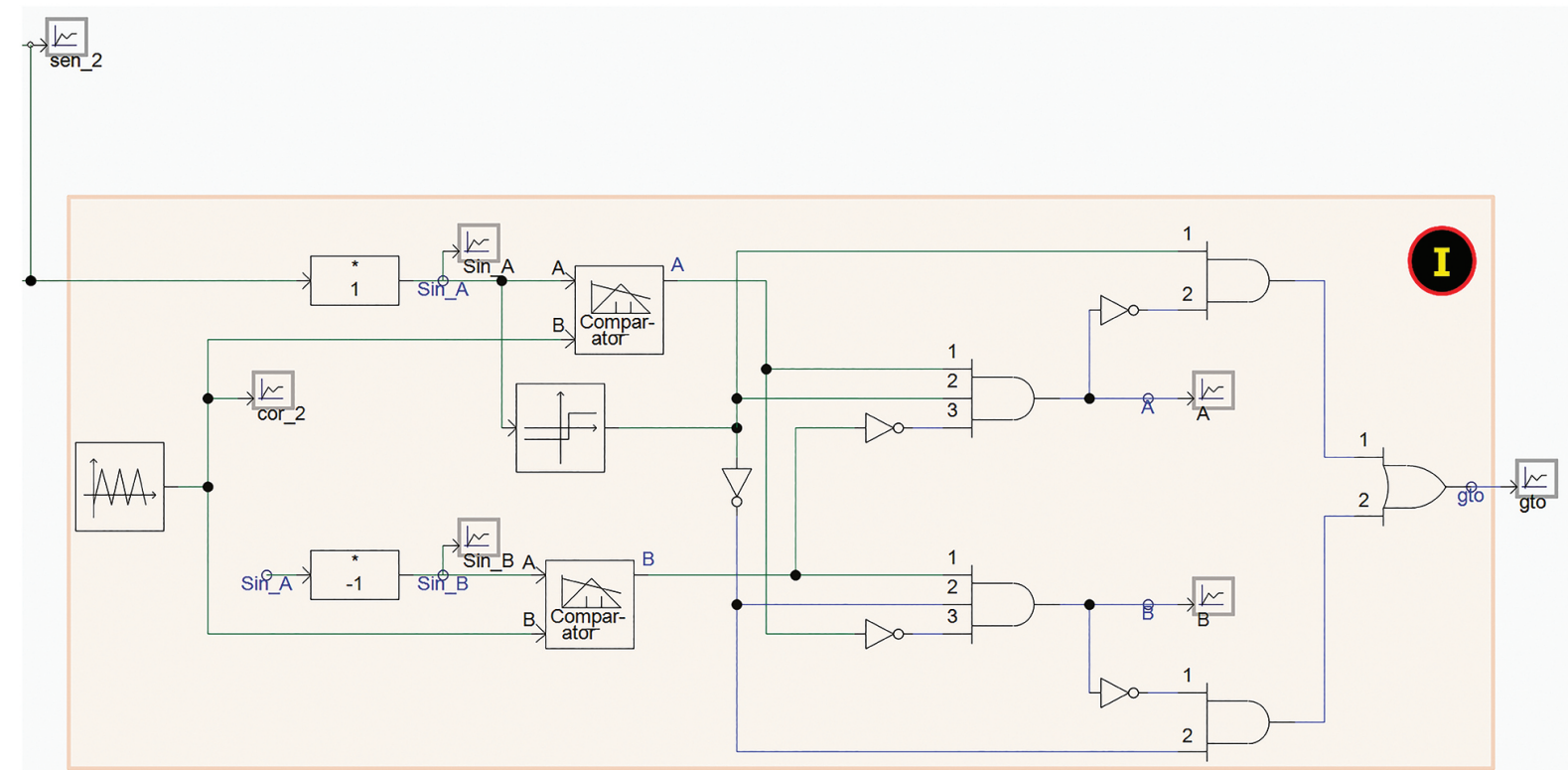

Fig. 11. SPWM control of power DC/AC full-bridge converter implemented in the PSCAD. SPWM, sinusoidal pulse width modulation.

switching SPWM. This technique allows a low total harmonic distortion and shifting the generated harmonics to high frequencies, improving the elaboration of suppression filters (Massawe, 2013; Guo et al., 2019). Additionally, it allows the control of the output voltage through modulating the amplitude of the reference sinusoidal signal (Barbi, 2008; Hart, 2010; Xiao, 2017; Youssef, et al., 2020). The unipolar switching SPWM strategy uses two signals to create the transistor drive SPWM modulation: a sinusoidal reference signal called modulation or control signal $\left(\mathrm{v}_{\mathrm{sin}}\right)$ 
and a second triangular signal used for high-frequency switching called carrier signal $\left(\mathrm{v}_{\mathrm{tri}}\right)$ (Barbi, 2008; Hart, 2010; Massawe, 2013; Youssef, et al., 2020). Figure 13 shows the two signals.

In unipolar switching SPWM modulation, transistors are switching to produce a positive semi cycle and a negative semi cycle considering the zero level and supply voltage $V_{d c}$. Eq. (3) presents the switching scheme of the transistors according to Figure 12.

$$
\left\{\begin{array}{l}
T_{1} \rightarrow " 1 ", \text { if } v_{s i n}>v_{t r i} \\
T_{4} \rightarrow " 1 ", \text { if }-v_{s i n}<v_{t r i} \\
T_{3} \rightarrow " 1 ", \text { if }-v_{s i n}>v_{t r i} \\
T_{2} \rightarrow " 1 ", \text { if } v_{s i n}<v_{t r i}
\end{array}\right.
$$

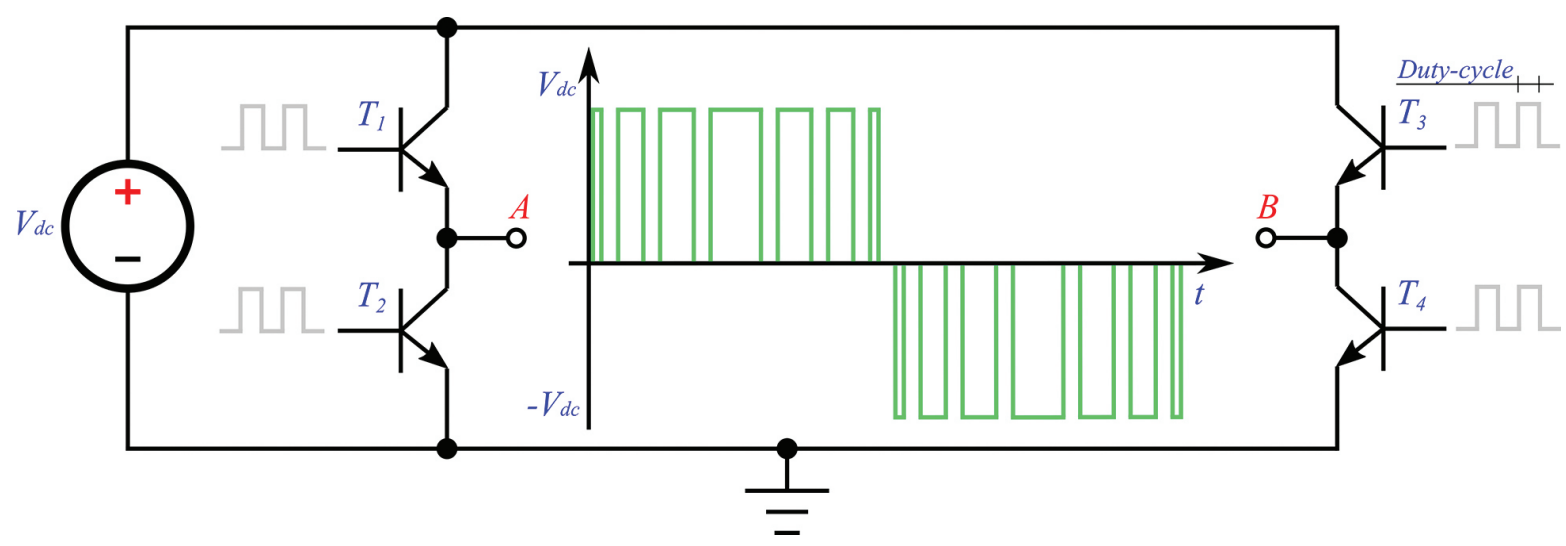

Fig. 12. Structure of full-bridge single-phase inverter using transistors with SPWM. SPWM, sinusoidal pulse width modulation.

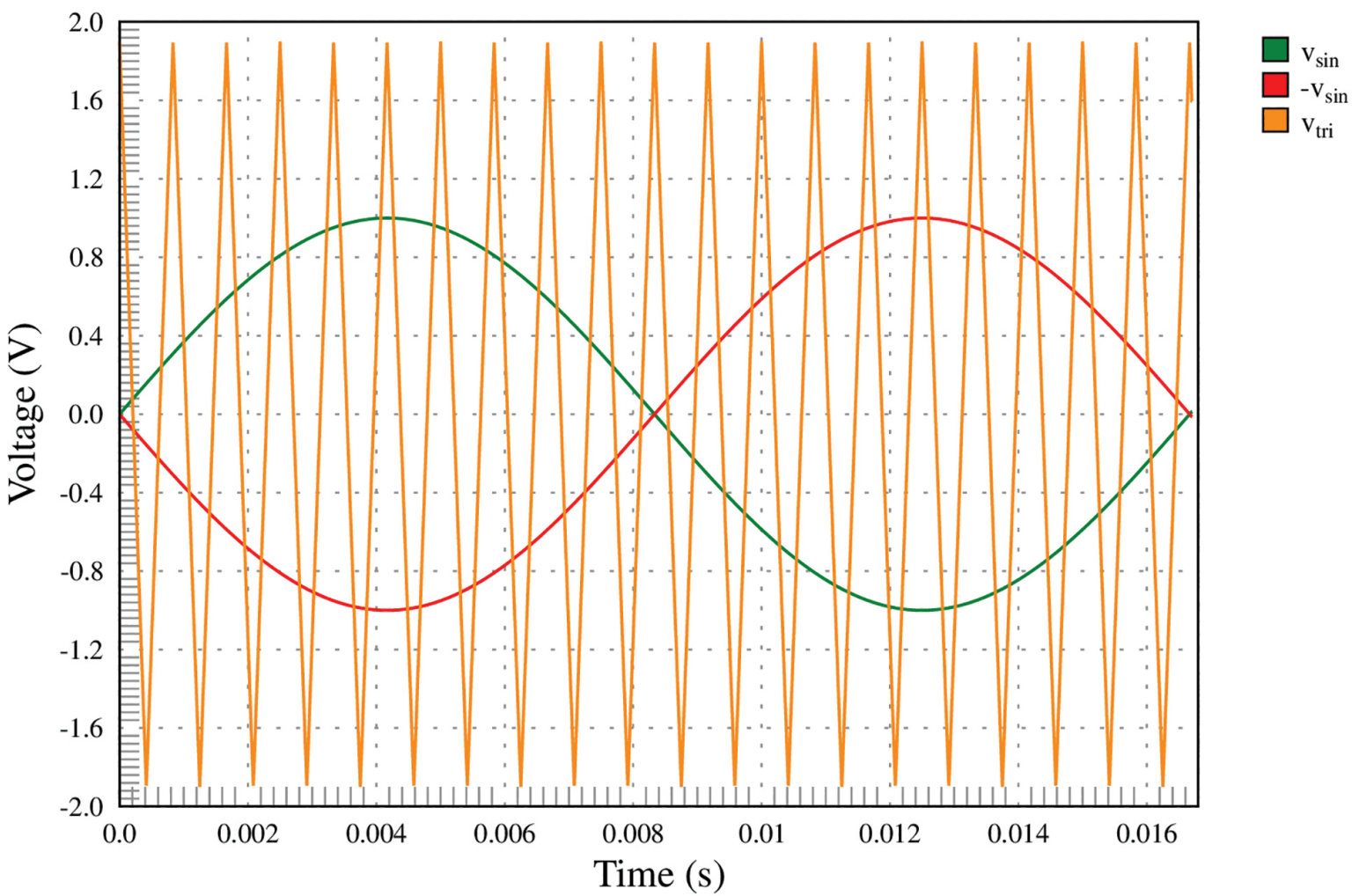

Fig. 13. Signals $V_{\text {sin }}$ e $V_{\text {tri }}$ used to create SPWM. SPWM, sinusoidal pulse width modulation. 
where $T_{x}$ is the transistor's binary logic shift; $v_{\text {sin }}$ is the control signal; and $v_{\text {tri }}$ is the carrier signal.

According to the logic of Eq. (3) and the control implemented in stage I through logic gates, the positive and negative semi cycle signals are obtained between points A-B as shown in Figures 12 and 14.

Unipolar switching SPWM modulation has only the disadvantage of requiring a complex circuit to elaborate control signals for transistors and also a progressive increase of thermal losses with increased frequency of the carrier signal $\left(\mathrm{v}_{\text {tri }}\right)$.

An important parameter regarding control signal ratio $\left(v_{\sin }\right)$ and carrier signal $\left(v_{t r i}\right)$ is the modulation frequency rate $\left(m_{f}\right)$, being important for the determination of harmonics and the best output filter configuration of the DC/AC converter. The modulation frequency rate $\left(m_{f}\right)$ may be calculated according to Eq. (4) (Massawe, 2013; Luo and Ye, 2017; Xiao, 2017; Youssef, et al., 2020):

$$
m_{f}=\frac{f_{\text {tri }}}{f_{\text {sin }}}
$$

where $f_{t r i}$ is the carrier signal frequency and $f_{\text {sin }}$ is the control signal frequency.

Another relevant parameter is the amplitude modulation rate $\left(\mathrm{m}_{\mathrm{a}}\right)$, which is important for the determination of the amplitude voltage of the fundamental output frequency, given by Eq. (5) (Luo and Ye, 2017; Xiao, 2017; Youssef, et al., 2020):

$$
m_{a}=\frac{v_{m, s i n}}{v_{m, t r i}}
$$

where $v_{m, s i n}$ is the control signal voltage amplitude and $v_{m, t r i}$ is the carrier signal voltage amplitude.

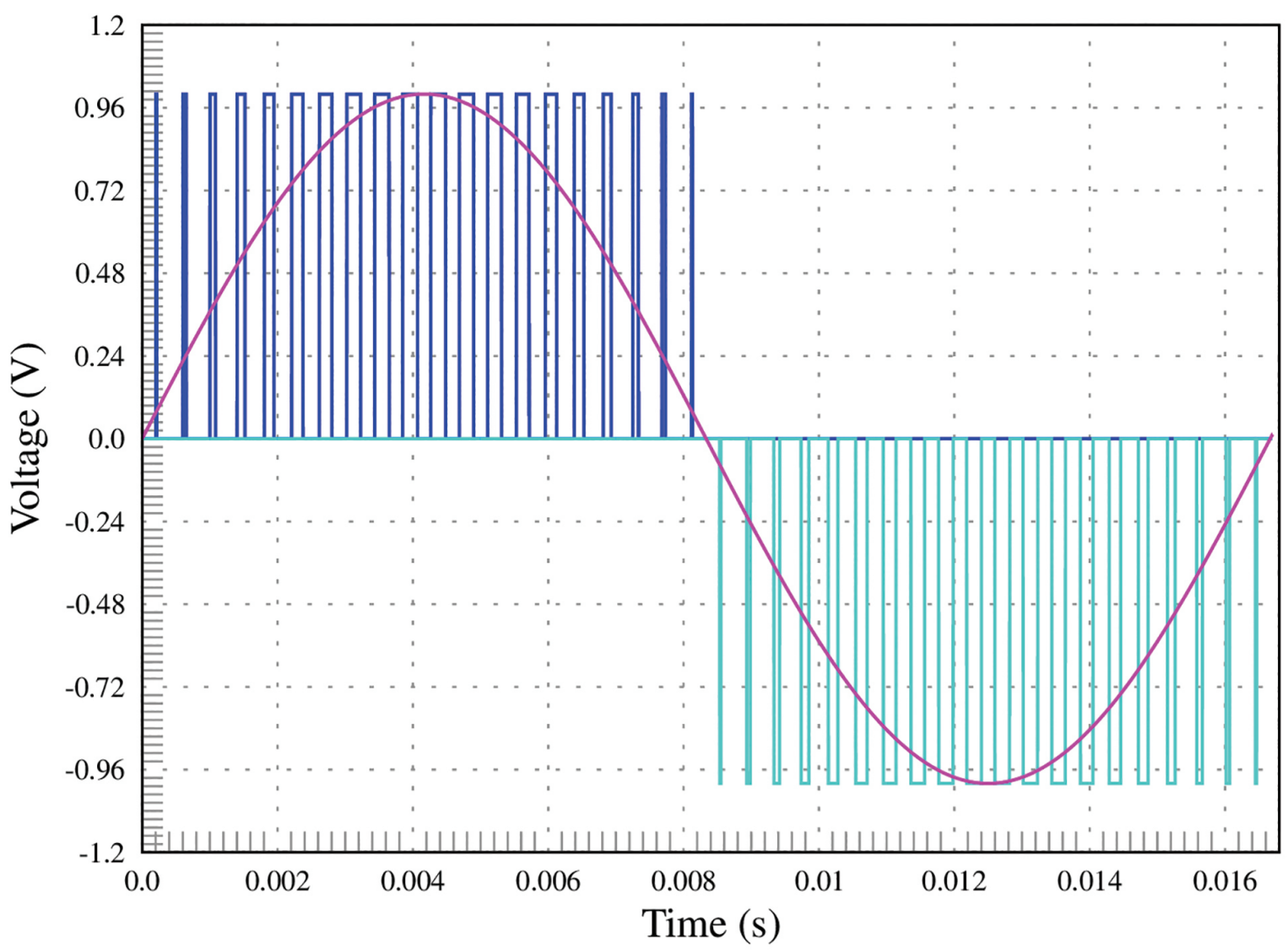

Fig. 14. SPWM used in unipolar switching. SPWM, sinusoidal pulse width modulation. 


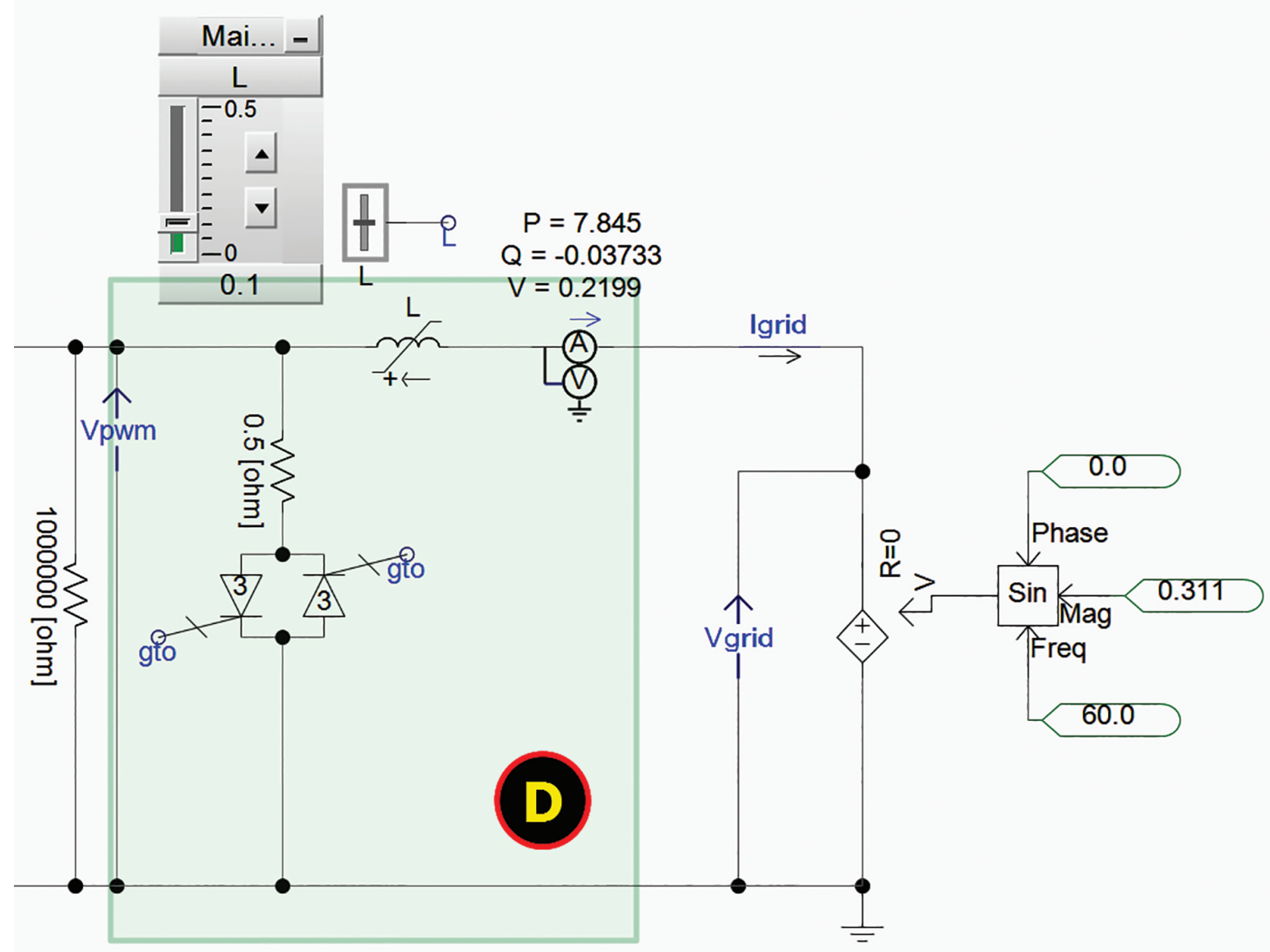

Fig. 15. AC power coupling and grid-connected implementation in the PSCAD.

Stage $\mathbf{D}$ - refers to the DC/AC converter and AC power coupling, and its electrical schematic implemented in the PSCAD is depicted in Figure 15.

The control of the current supplied to the AC power is performed by regulating the voltage between the points $\mathrm{A}-\mathrm{B}\left(\mathrm{V}_{\mathrm{AB}}\right)$ (as shown in Figure 12). It is applied between the coupling inductor and the AC power. The coupling inductor can be determined according to Eq. (6) (Massawe, 2013; Salem and Atia, 2015; Xiao, 2017; Hassaine and Bengourina, 2020).

$$
L \frac{\Delta i_{L}}{\Delta t}=V_{a b}-V_{\text {grid }} \rightarrow L=\frac{\left(V_{a b}-V_{\text {grid }}\right)}{\left(\frac{\Delta i_{L}}{\Delta t}\right)}
$$

where $L$ is the output inductor; $\Delta i_{L}$ is the variation of the output current through the output inductor; $\Delta t$ is the variation of the time; $V_{a b}$ is the voltage between A-B points; and $V_{\text {grid }}$ is the alternating voltage from AC power.

Before the inductor connected to the electrical grid, two gate turn-off (GTO) thyristors were placed in antiparallel to provide a zero volt stage, discharging the electromagnetic energy stored by the inductor during the switching of the $T_{1}, T_{2}, T_{3}$ and $T_{4}$ transistors (Massawe, 2013; Gerardo, et al., 2015; Salem and Atia, 2015; Guo et al., 2019).

\subsection{Control stage}

Figure 16 shows the block structure of the control system stages implemented in the PSCAD/EMTDC software for control of the single-phase inverter.

Stages E, F, G - stages $E$ and F are two independent phase generators (PG) and their electrical schematics implemented in the PSCAD are represented in Figures 17 and 18. 


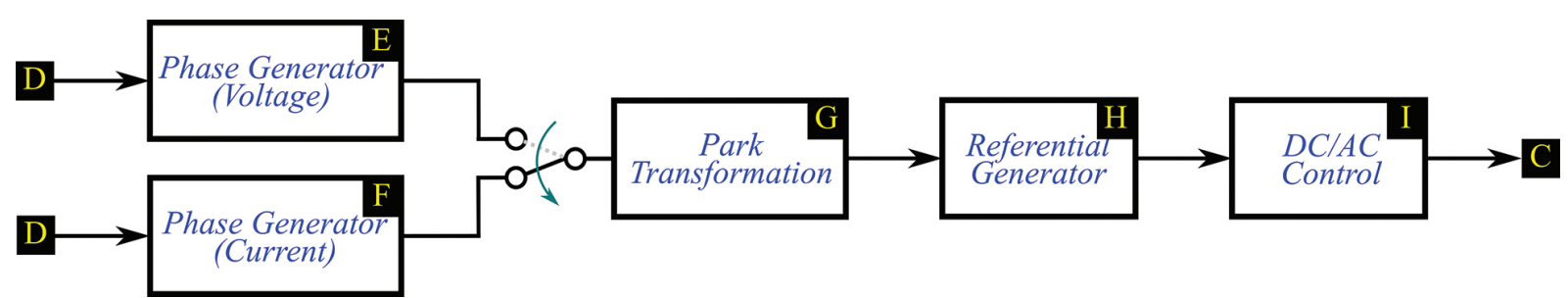

Fig. 16. Control stages of $P G$ (current and voltage), park transformation, $R G$ and $D C / A C$ control system. $P G$, phase generator; $R G$, reference generator.

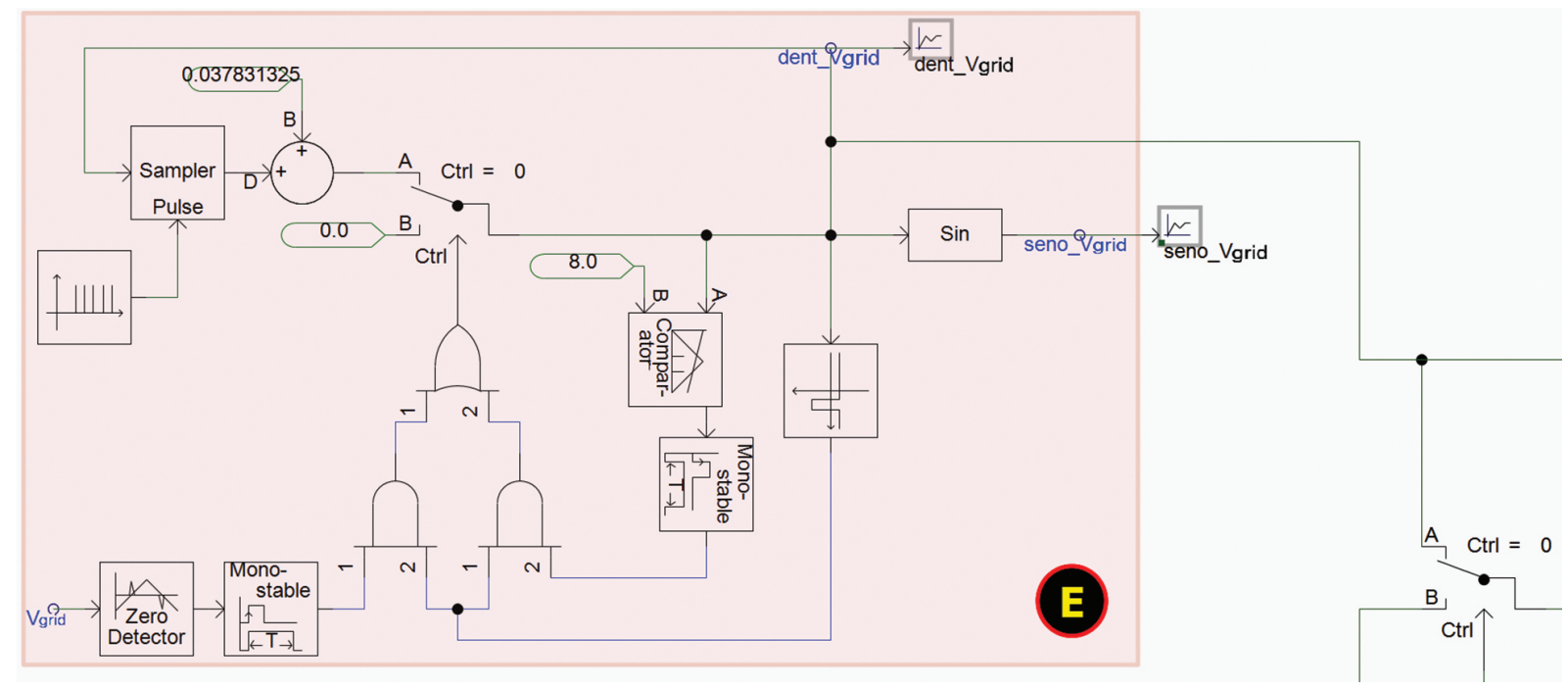

Fig. 17. Control stage of PG voltage implemented in the PSCAD. PG, phase generator.

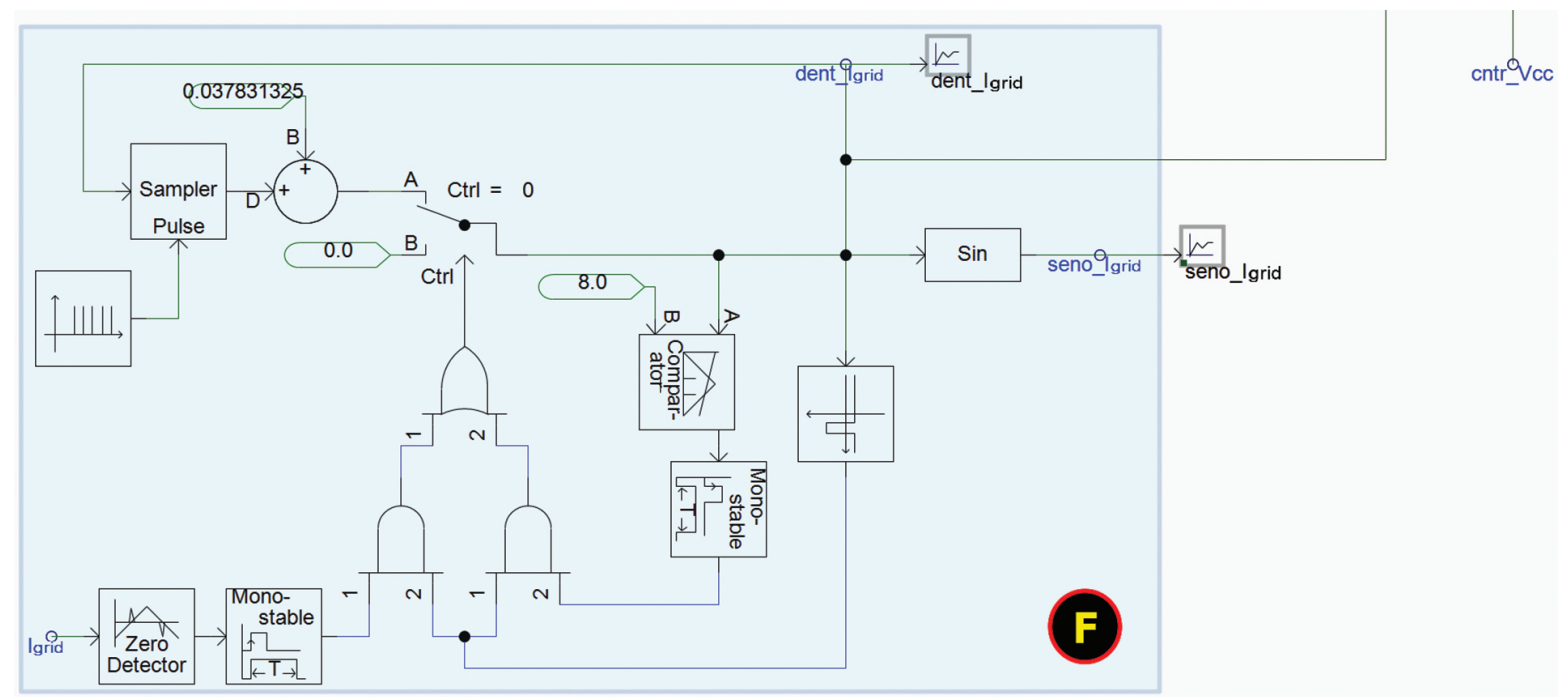

Fig. 18. Control stage of $P G$ current implemented in the PSCAD. PG, phase generator.

The phase generator of stage $E$ transforms the sine voltage signal from the $A C$ power $\left(\mathrm{V}_{\text {grid }}\right)$ in an angular signal $\theta$ from 0 to $2 \pi$. This is used for synchronisation by Park transformation and inverse Park transformation. Stage $F$ phase generator transforms the signal of the sine current from the DC/AC converter output $\left(I_{\text {grid }}\right)$ in an angular signal $\theta$ from 0 to $2 \pi$, which is used to generate the sine signal for the $\alpha$ input of the Park transformation and also 
to generate an advance $90^{\circ}$ sine signal used by the $\beta$ input of the same. In Figures 19 and 20, the signs $V_{\text {grid }} I_{\text {grid' }}$ dent_ $V_{\text {grid }}$ and dent_ $I_{\text {grid }}$ used in the Park transformation (stage $G$ ) are shown.

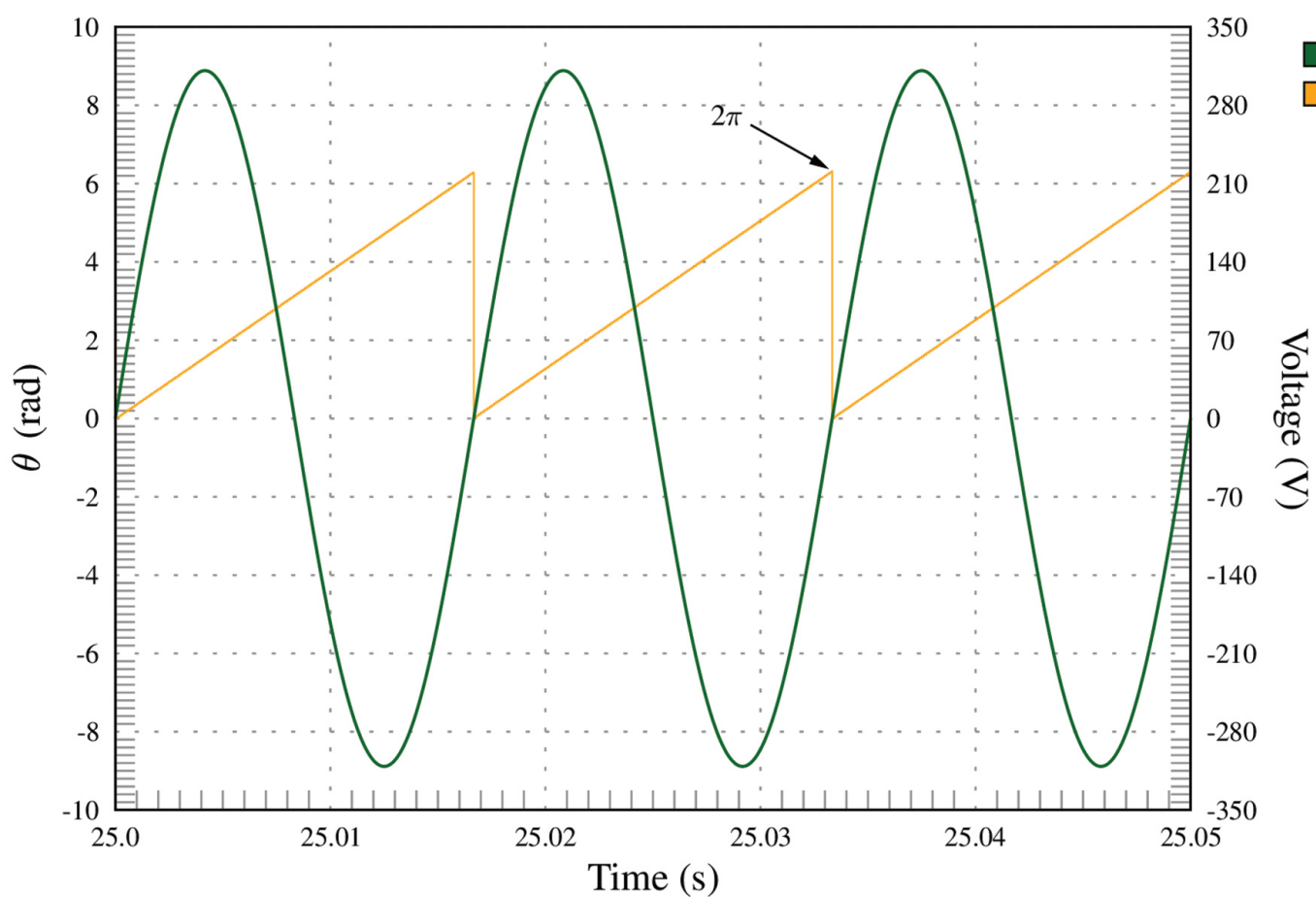

Fig. 19. $P G$ from voltage $\left(V_{\text {grid }}\right)$. $P G$, phase generator.

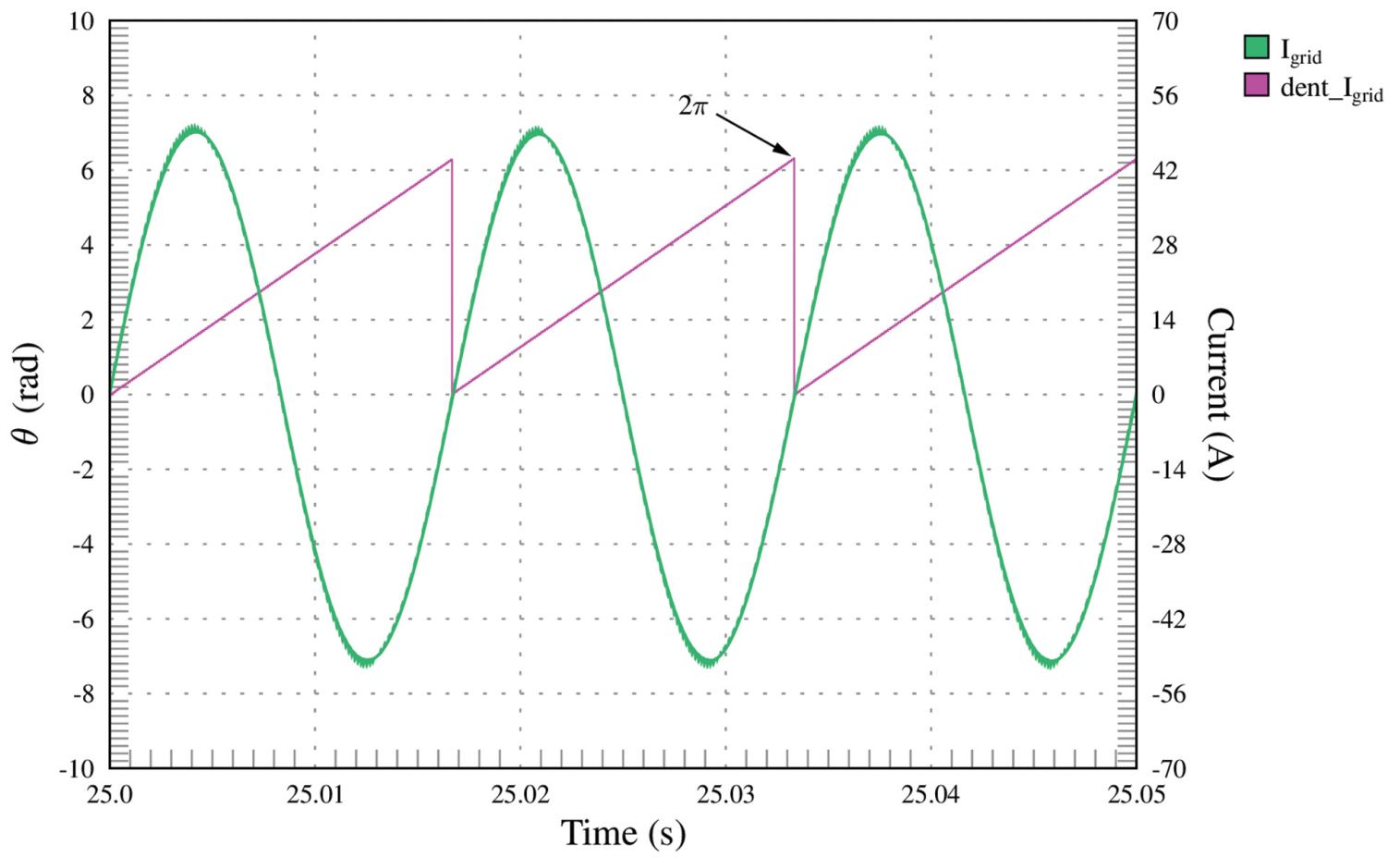

Fig. 20. $P G$ from current $\left(I_{\text {grid }}\right) \cdot P G$, phase generator. 
Stage $\mathrm{G}$ consists of the control system CPQC based on the Park transformation and its electrical schematic implemented in the PSCAD is depicted in Figure 21 (Monfared, et al., 2012; Gajewski and Pienkowski, 2016; Manitoba HVDC Research Centre, 2018; Hairi, 2019).

In this control system, active and reactive power component errors from $\mathrm{I}_{\text {grid }}$ and $\mathrm{V}_{\text {grid }}$ signals are generated by a wattmeter (Monfared, et al., 2012; Manitoba HVDC Research Centre, 2018). For this, the Park transformation through Eq. (7) is used.

$$
\left[\begin{array}{l}
v_{d} \\
v_{q}
\end{array}\right]=\left[\begin{array}{cc}
\cos \theta & \sin \theta \\
-\sin \theta & \cos \theta
\end{array}\right] v_{\beta}
$$

where $v_{\alpha}$ and $v_{\beta}$ refer to two-axis stationary and $v_{d}$ and $v_{q}$ refer to rotary reference frames, both using Park transformation.

The signals $v_{d}$ and $v_{q}$ are compared to the reference values of reactive power $\left(Q_{\text {load }}\right)$ and active power $\left(P_{\text {load }}=0\right)$, and then inserted into a proportional-integral controller (PI) together with the inverse Park transformation (Monfared, et al., 2012; Manitoba HVDC Research Centre, 2018; Hairi, 2019). The latter generates two sinusoidal signals $v_{\alpha}$ and $v_{\beta}$ and these are scaled in both amplitude and angular displacement, which will be used as a reference $\left(v_{\text {sin }}\right)$ for the unipolar PWM signal generation to control the DC/AC converter transistors. The signals $\mathrm{v}_{\alpha}$ and $\mathrm{v}_{\beta}$ generated by the inverse Park transformation are according to Eq. (8). The signal $v_{\beta}$ is not used by the control system.

$$
\left[\begin{array}{l}
v_{\alpha} \\
v_{\beta}
\end{array}\right]=\left[\begin{array}{cc}
\cos \theta & -\sin \theta \\
\sin \theta & \cos \theta
\end{array}\right] v_{d}
$$

where $v_{\alpha}$ and $v_{\beta}$ refer to two-axis stationary and $v_{d}$ and $v_{q}$ refer to rotary reference frames, both using Park transformation.

Due to the feedback current control, the CPQC control system allows optimal control dynamics and guaranteed static performance (Monfared, et al., 2012; Gajewski and Pienkowski, 2016; Manitoba HVDC Research Centre, 2018; Hairi, 2019).

When the $\mathrm{I}_{\text {grid }}$ current is injected into AC power, it must be exactly in phase with the $\mathrm{V}_{\text {grid }}$ voltage, or even the $\mathrm{I}_{\text {grid }}$ current must have the ability to advance or delay its phase, aiming to maintain a unit power factor (Simões and Farret, 2017; Xiao, 2017). Thus, the E, F and G systems constitute the PLL responsible for synchronisation

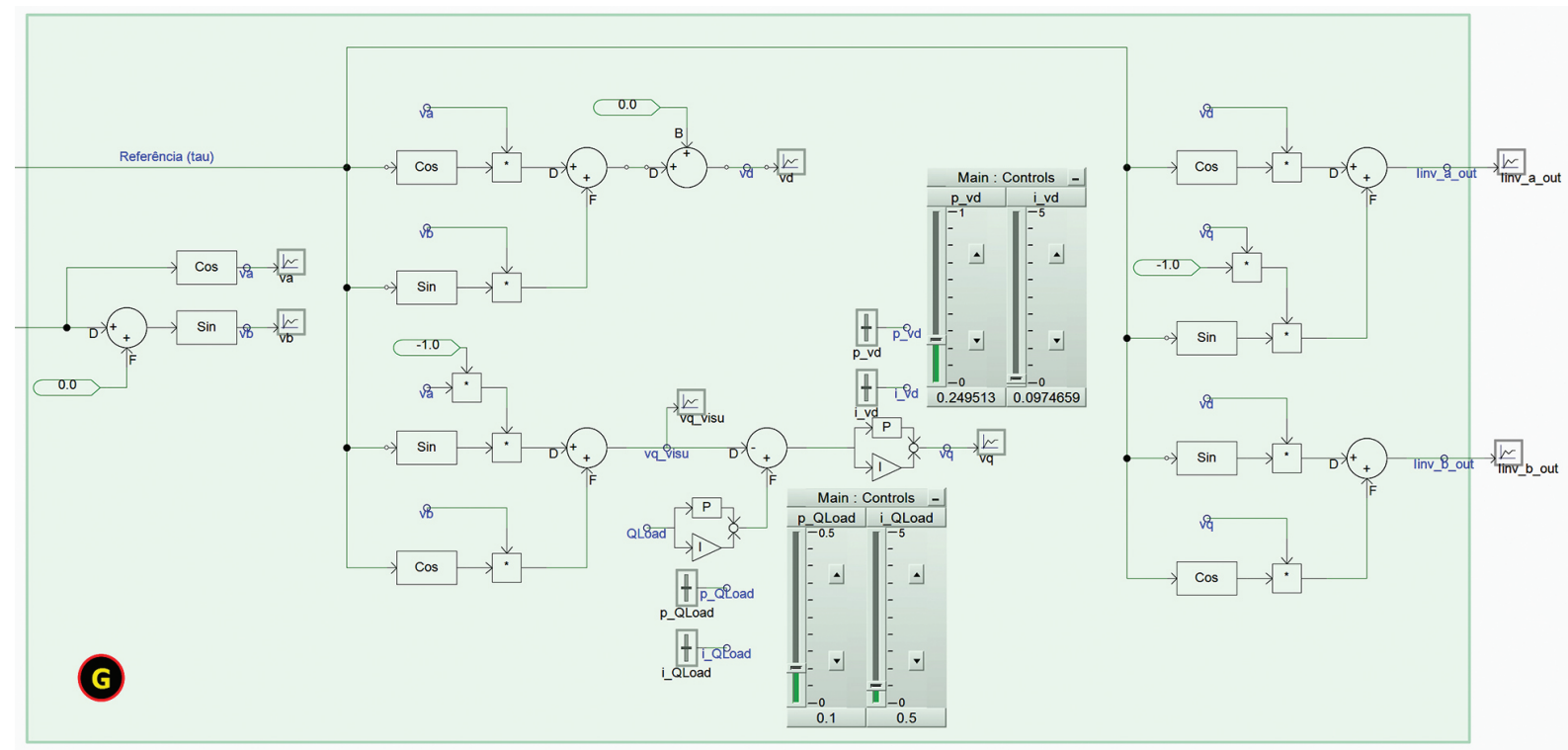

Fig. 21. Control system $C P Q C$ based on the park transformation. $C P Q C$, constant $P-Q$ control. 
between the $I_{\text {grid }}$ current and the $V_{\text {grid }}$ voltage, always allowing a power factor of 1 , even with the addition of capacitive or inductive loads (Gajewski and Pienkowski, 2016). In this way, the circuits are always performing the maximum power transfer between the photovoltaic module and the AC power (Simões and Farret, 2017; Hairi, 2019).

Stage $\mathbf{H}$ - the electrical schematic of stage $\mathrm{H}$ implemented in the PSCAD is depicted in Figure 22.

The implementation of this circuit is necessary due to the fact that PSCAD/EMTDC software requires a referential generator to $v_{\text {sin }}$ sine signal. The $I_{\text {inv_a _out }}$ signal $\left(v_{\alpha}\right)$ generated by the referential generator (sen_2) is used by stage I and has both phase and amplitude modulation displacement. Therefore, the signal control implemented in stage $\mathrm{H}$ (sen_2) reproduces exactly these changes from $\mathrm{I}_{\text {inv_a_out }}$ signal $\left(\mathrm{v}_{\mathrm{a}}\right)$.

\section{Simulations and Results}

To validate the theoretical foundations and functionality of the proposed DC/AC converter in the PSCAD/EMTDC software, simulations were performed for solar irradiance at values of $100 \mathrm{~W} / \mathrm{m}^{2}, 200 \mathrm{~W} / \mathrm{m}^{2}, 400 \mathrm{~W} / \mathrm{m}^{2}, 600 \mathrm{~W} / \mathrm{m}^{2}$, $800 \mathrm{~W} / \mathrm{m}^{2}$ and $1,000 \mathrm{~W} / \mathrm{m}^{2}$ with a fixed temperature of $25^{\circ} \mathrm{C}$. Figures 23 and 24 show the values of $V_{p v}$ and $\mathrm{I}_{\mathrm{pv}}$ for the maximum power point for the selected solar irradiances.

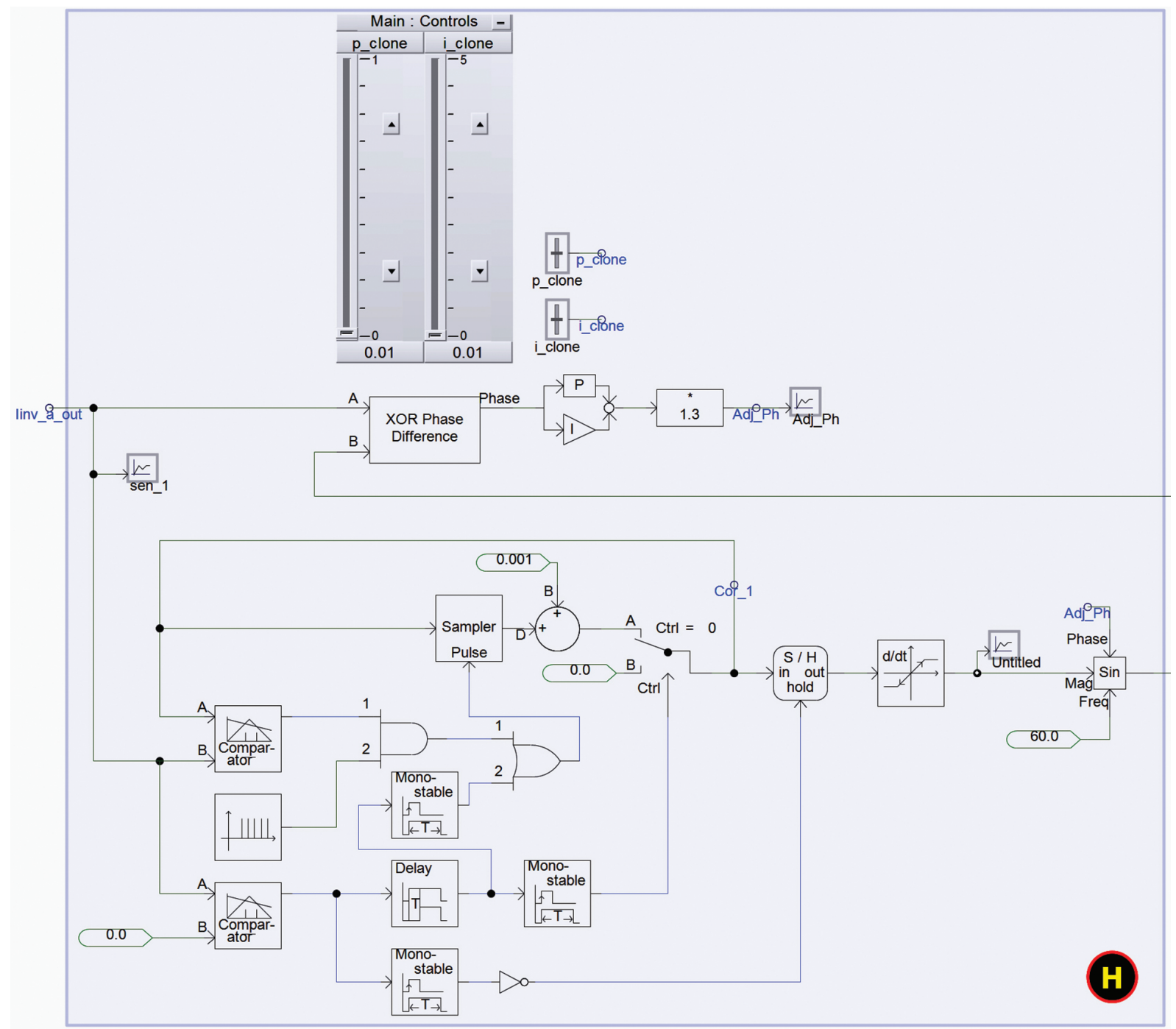

Fig. 22. Control of $R G$ to $v_{\text {sin }}$ sine signal implemented in the PSCAD. RG, reference generator. 

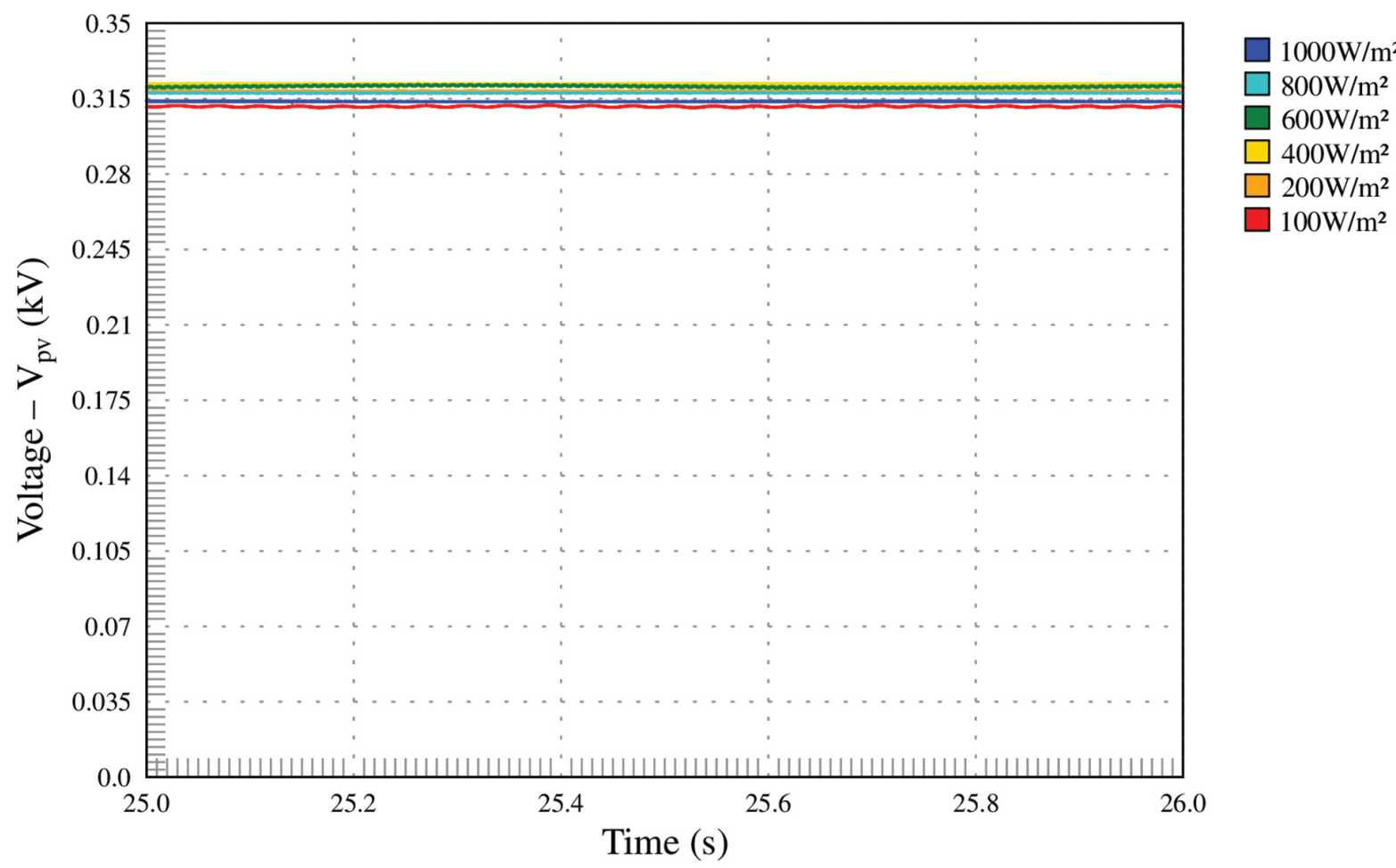

Fig. 23. $\mathrm{V}_{\mathrm{pv}}$ response curves for solar irradiances of $1,000 \mathrm{~W} / \mathrm{m}^{2}, 800 \mathrm{~W} / \mathrm{m}^{2}, 600 \mathrm{~W} / \mathrm{m}^{2}, 400 \mathrm{~W} / \mathrm{m}^{2}, 200 \mathrm{~W} / \mathrm{m}^{2}$ and $100 \mathrm{~W} / \mathrm{m}^{2}$ at $25{ }^{\circ} \mathrm{C}$

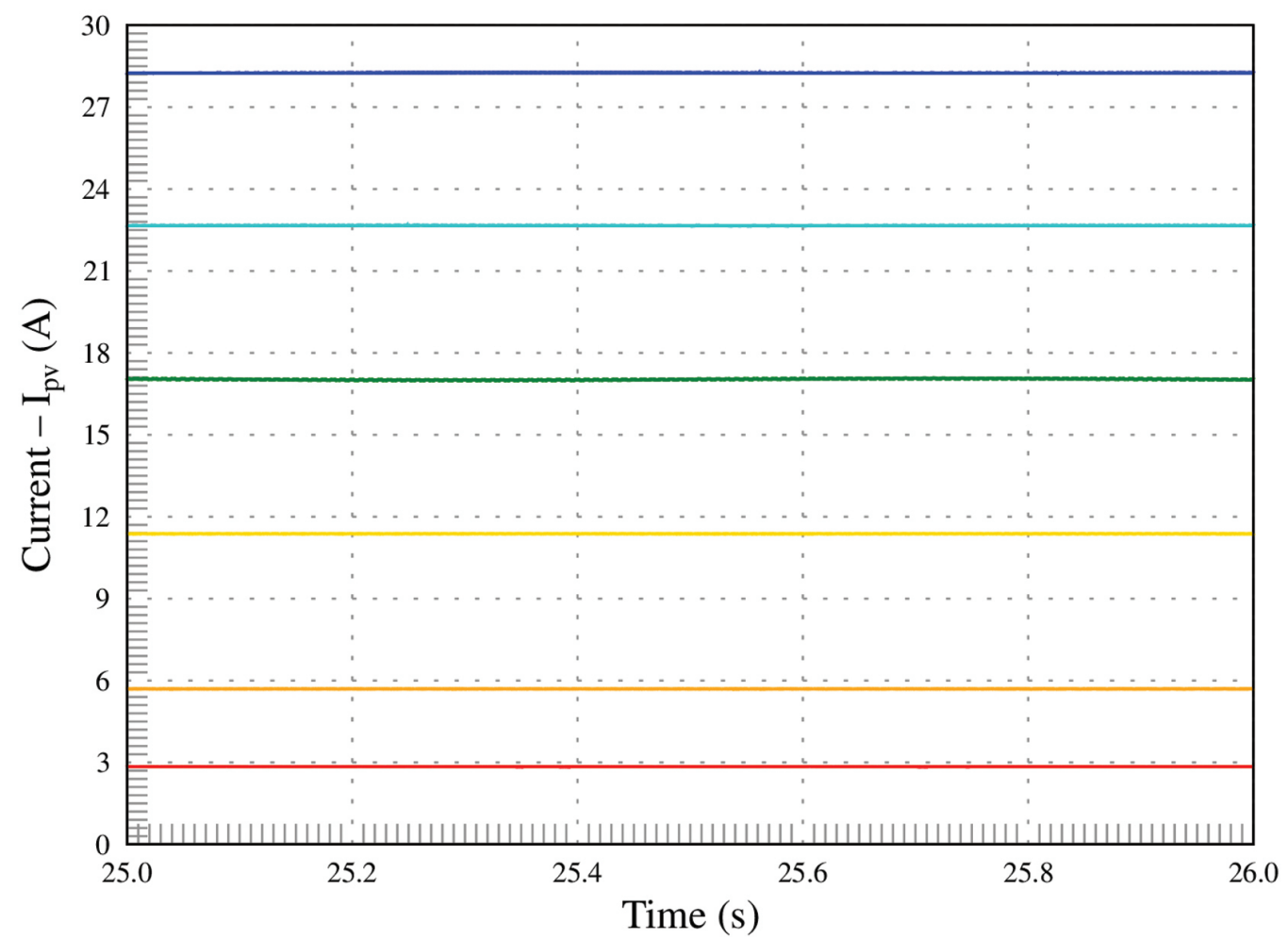

$\square 1000 \mathrm{~W} / \mathrm{m}^{2}$

$\square 800 \mathrm{~W} / \mathrm{m}^{2}$

$600 \mathrm{~W} / \mathrm{m}^{2}$

$\square 400 \mathrm{~W} / \mathrm{m}^{2}$

$\square 200 \mathrm{~W} / \mathrm{m}^{2}$

$\square 100 \mathrm{~W} / \mathrm{m}^{2}$

Fig. 24. $I_{\text {pv }}$ response curves for solar irradiances of $1,000 \mathrm{~W} / \mathrm{m}^{2}, 800 \mathrm{~W} / \mathrm{m}^{2}, 600 \mathrm{~W} / \mathrm{m}^{2}, 400 \mathrm{~W} / \mathrm{m}^{2}, 200 \mathrm{~W} / \mathrm{m}^{2}$ and $100 \mathrm{~W} / \mathrm{m}^{2}$ at $25^{\circ} \mathrm{C}$. 
According to the $\mathrm{V}_{\mathrm{pv}}$ and $\mathrm{I}_{\mathrm{pv}}$ values seen in Figure 5 by the individual simulation of the photovoltaic modules, it is verified that the values obtained in the DC/DC converter input are exactly equal to those of the simulation, proving the effectiveness of mppt control and control of the DC/DC Full-Bridge converter, implemented in stage J.

Table 2 shows the displacement angles $(\theta)$ between $I_{\text {grid }}$ current and $V_{\text {grid }}$ voltage, the photovoltaic array power, active and reactive power for selected irradiance levels.

The phase angle $\theta$ presented an advance or delay always $<1^{\circ}$, keeping the power factor practically around the unit for any irradiance value. Thus, the efficiency and dynamics of the PLL control system based on the Park transformation, as elaborated in stages $\mathrm{E}, \mathrm{F}$ and $\mathrm{G}$ of Figure 16 , are verified.

Figure 25 presents the DC/AC converter efficiency values according to the ratio of the converter output power and maximum power, where multiple irradiances of $100 \mathrm{~W} / \mathrm{m}^{2}$ were highlighted.

Comparing the DC/AC converter implemented in the PSCAD with current commercial DC/AC converters, it is verified that the yield is equivalent or superior. Around $10 \%$ of its maximum capacity (irradiance of $100 \mathrm{~W} / \mathrm{m}^{2}$ ) the conversion efficiency is approximately $95 \%$. With an irradiance of $1,000 \mathrm{~W} / \mathrm{m}^{2}$, which in the particular case is around $76 \%$ of its maximum capacity, the converter efficiency is $86 \%$. With these simulated results, the effectiveness of stages $\mathrm{C}$ and $\mathrm{I}$ of the DC/AC converter is confirmed. The $\mathrm{V}_{\mathrm{dc}}$ and $\mathrm{I}_{\mathrm{dc}}$ outputs of the DC/DC converter are demonstrated in Figures 26 and 27.

For the solar irradiance range evaluated, the voltage $\mathrm{V}_{\mathrm{dc}}$ has become practically stable due to the duty-cycle increase of PP1 and PP2 signals used for transistors switching at stage B. For the $I_{d c}$ current, only at an irradiance of $100 \mathrm{~W} / \mathrm{m}^{2}$, a small ripple is verified due to the reduction of duty-cycle switching of the same signals. However, this ripple did not present problems for the generation of $\mathrm{I}_{\text {grid }}$ output current, due to the filtration performed by stages $\mathrm{C}$ and D. $V_{\text {pwm }}$ voltages are shown in Figure 28.

To illustrate the general behaviour of the proposed inverter, this paper will present the $V_{p w m}$ voltages for fixed solar irradiances of $100 \mathrm{~W} / \mathrm{m}^{2}, 600 \mathrm{~W} / \mathrm{m}^{2}$ and $1,000 \mathrm{~W} / \mathrm{m}^{2}$, all at a fixed temperature of $25^{\circ} \mathrm{C}$. The output voltages of the DC/AC converter $\left(\mathrm{V}_{\mathrm{pwm}}\right)$, for each adjusted irradiance, showed good stability and did not suffer interference in their amplitudes by the ripple voltages from the $V_{d c}$ voltage of stage $B$. In this way, the right choice of the output filter and transistor switching circuit in stage $I$ is proved.

Still on stage I, Figure 29 shows the use and non-use of GTO thyristors before the inductor coupling with the AC power.

According to Figure 29, the use of GTO thyristors presented an excellent alternative in promoting the discharge of the electromagnetic energy stored by the inductor. The latter occurs during the switching to the logic level ' 1 ' of the $T_{1}, T_{2}, T_{3}$ and $T_{4}$. The $V_{p w m}$ do not present deformations or harmonics into output voltages of the DC/AC converter, as seen in Figures 29 and 30.

According to Figure 30 , the voltage $V_{\text {grid }}$ and current $I_{\text {grid }}$, which were supplied to the grid, did not present deformations or noise. This was possible due to the choice of a high switching frequency for the DC/AC converter

Table 2. Displacement angles $(\theta)$ between $V_{\text {grid }}$ e $I_{\text {grid }}$

\begin{tabular}{lcccc}
\hline $\begin{array}{l}\text { Solar irradiance Irrad } \\
\left(\mathrm{W} / \mathrm{m}^{2}\right)\end{array}$ & $\begin{array}{c}\text { Photovoltaic module } \\
\text { power }-\mathrm{P}_{\text {mpp }}(\mathrm{W})\end{array}$ & $\begin{array}{c}\text { Output active power } \\
\mathrm{P}(\mathrm{W})\end{array}$ & $\begin{array}{c}\text { Output reactive power } \\
\mathrm{Q}(\mathrm{Var})\end{array}$ & $\begin{array}{c}\text { Displacement angle between } \mathrm{I}_{\text {grid }} \\
\text { and } \mathrm{V}_{\text {grid }}(\mathrm{Degrees})\end{array}$ \\
\hline \hline 100 & 885.6 & 846.2 & -6.7 & -0.45 \\
200 & $1,813.2$ & $1,743.9$ & 23.0 & 0.75 \\
300 & $2,741.4$ & $2,621.9$ & 9.2 & 0.20 \\
400 & $3,661.4$ & $3,421.8$ & -16.7 & -0.27 \\
500 & $4,569.1$ & $4,247.6$ & 18.3 & 0.24 \\
600 & $5,460.8$ & $5,104.1$ & -4.7 & -0.05 \\
700 & $6,339.0$ & $5,735.6$ & 107.2 & 0.99 \\
800 & $7,198.9$ & $6,433.5$ & 18.9 & 0.16 \\
900 & $8,040.7$ & $7,034.8$ & 11.2 & 0.09 \\
1,000 & $8,863.9$ & $7,674.4$ & -20.4 & -0.15 \\
\hline
\end{tabular}




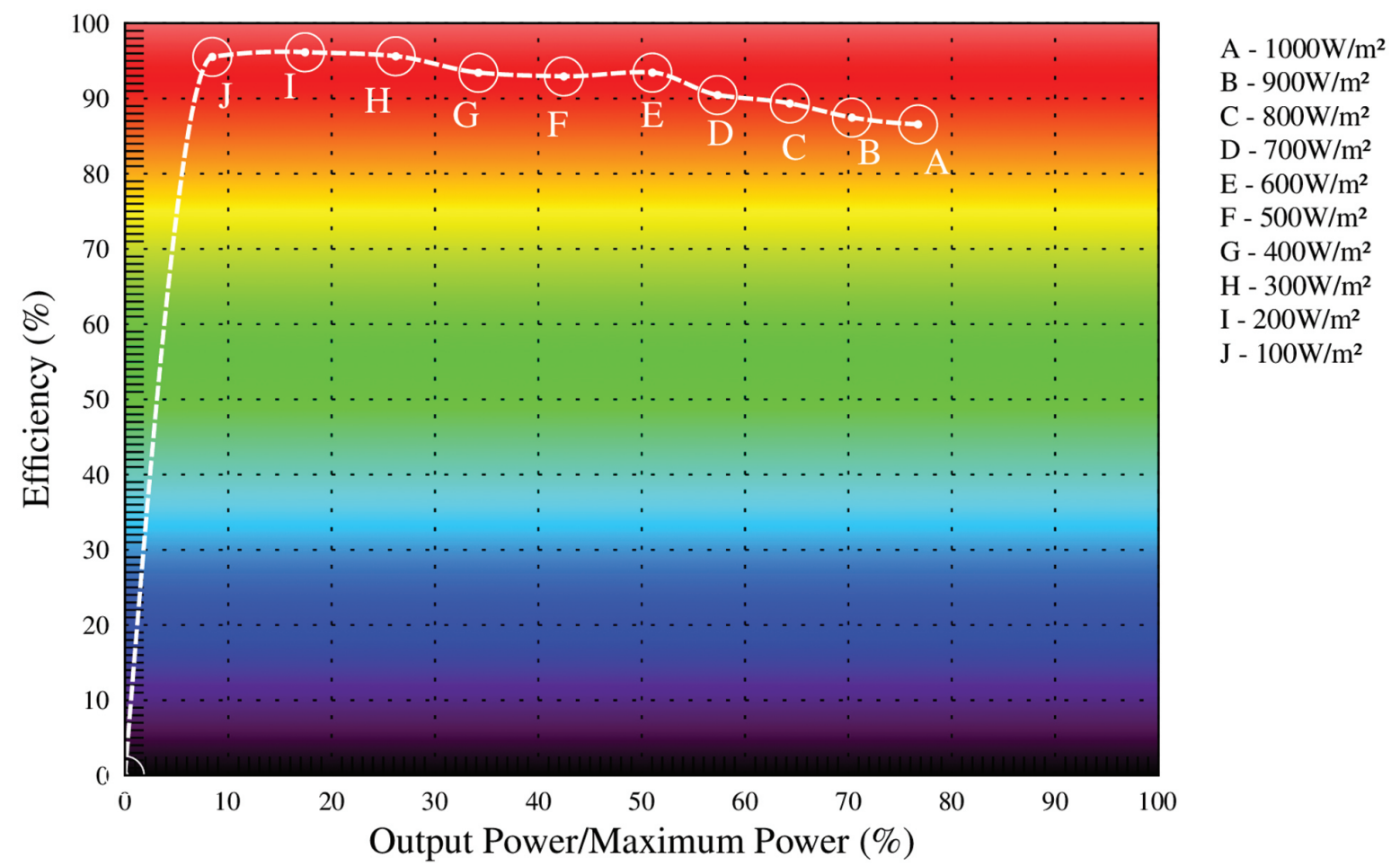

Fig. 25. Efficiency versus output/maximum power response curves for solar irradiations of $1,000 \mathrm{~W} / \mathrm{m}^{2}, 800 \mathrm{~W} / \mathrm{m}^{2}, 600 \mathrm{~W} / \mathrm{m}^{2}, 400 \mathrm{~W} / \mathrm{m}^{2}, 200 \mathrm{~W} / \mathrm{m}^{2}$ and $100 \mathrm{~W} / \mathrm{m}^{2}$ at $25^{\circ} \mathrm{C}$.

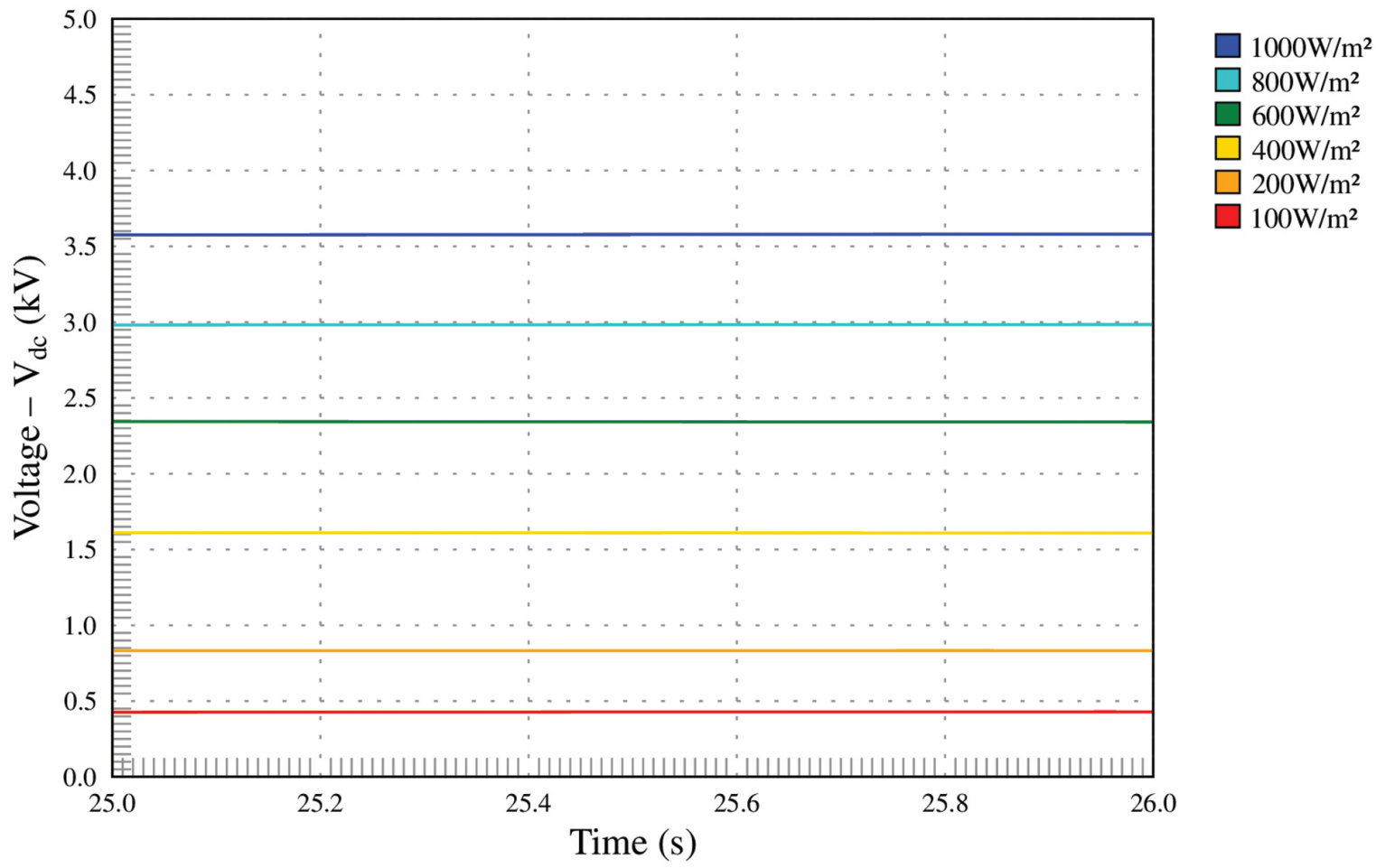

Fig. 26. $V_{d c}$ response curves for solar irradiances of $1,000 \mathrm{~W} / \mathrm{m}^{2}, 800 \mathrm{~W} / \mathrm{m}^{2}, 600 \mathrm{~W} / \mathrm{m}^{2}, 400 \mathrm{~W} / \mathrm{m}^{2}, 200 \mathrm{~W} / \mathrm{m}^{2}$ and $100 \mathrm{~W} / \mathrm{m}^{2}$ at $25^{\circ} \mathrm{C}$. 


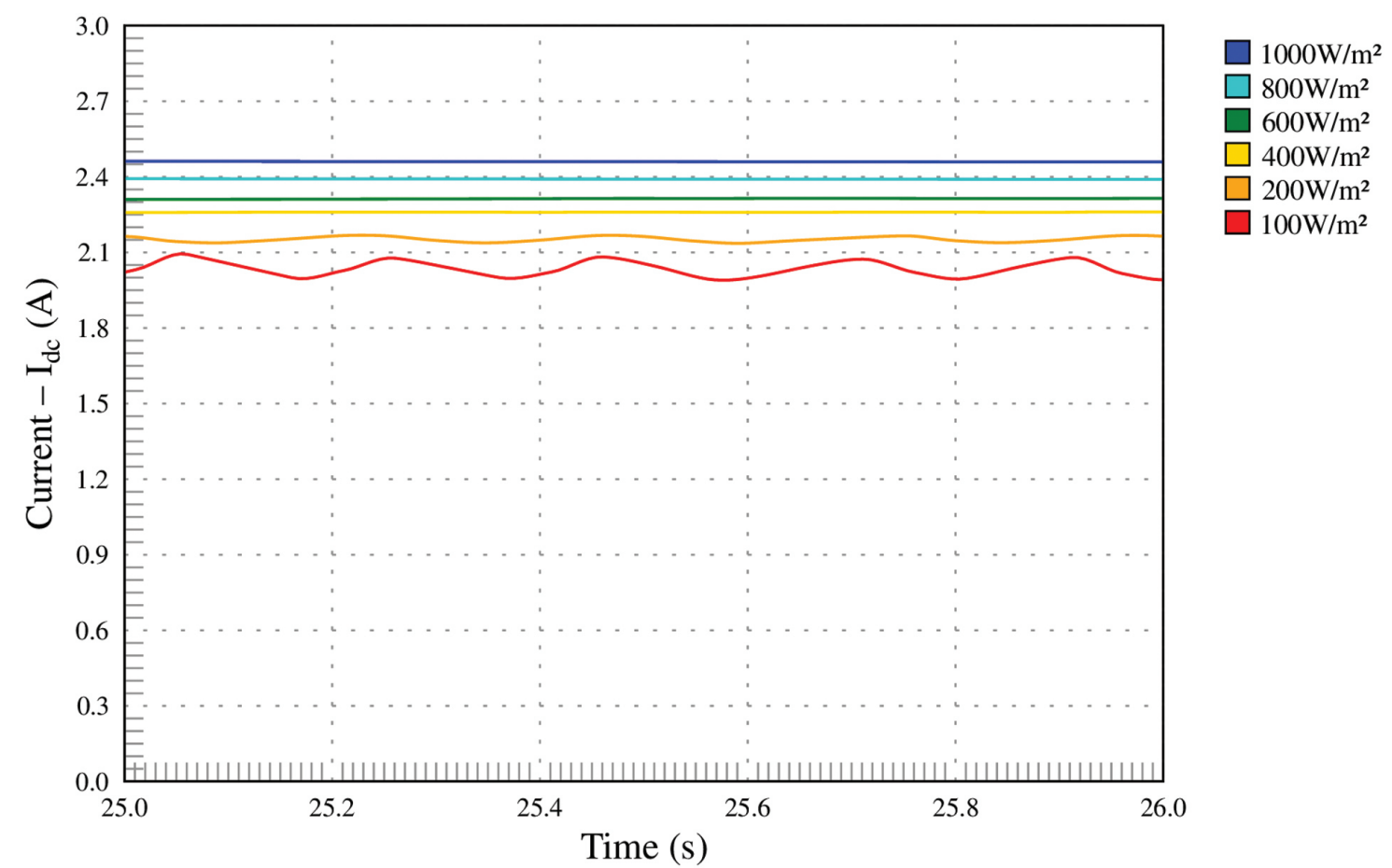

Fig. 27. $\left.\right|_{d c}$ response curves for solar irradiances of $1,000 \mathrm{~W} / \mathrm{m}^{2}, 800 \mathrm{~W} / \mathrm{m}^{2}, 600 \mathrm{~W} / \mathrm{m}^{2}, 400 \mathrm{~W} / \mathrm{m}^{2}, 200 \mathrm{~W} / \mathrm{m}^{2}$ and $100 \mathrm{~W} / \mathrm{m}^{2}$ at $25^{\circ} \mathrm{C}$.
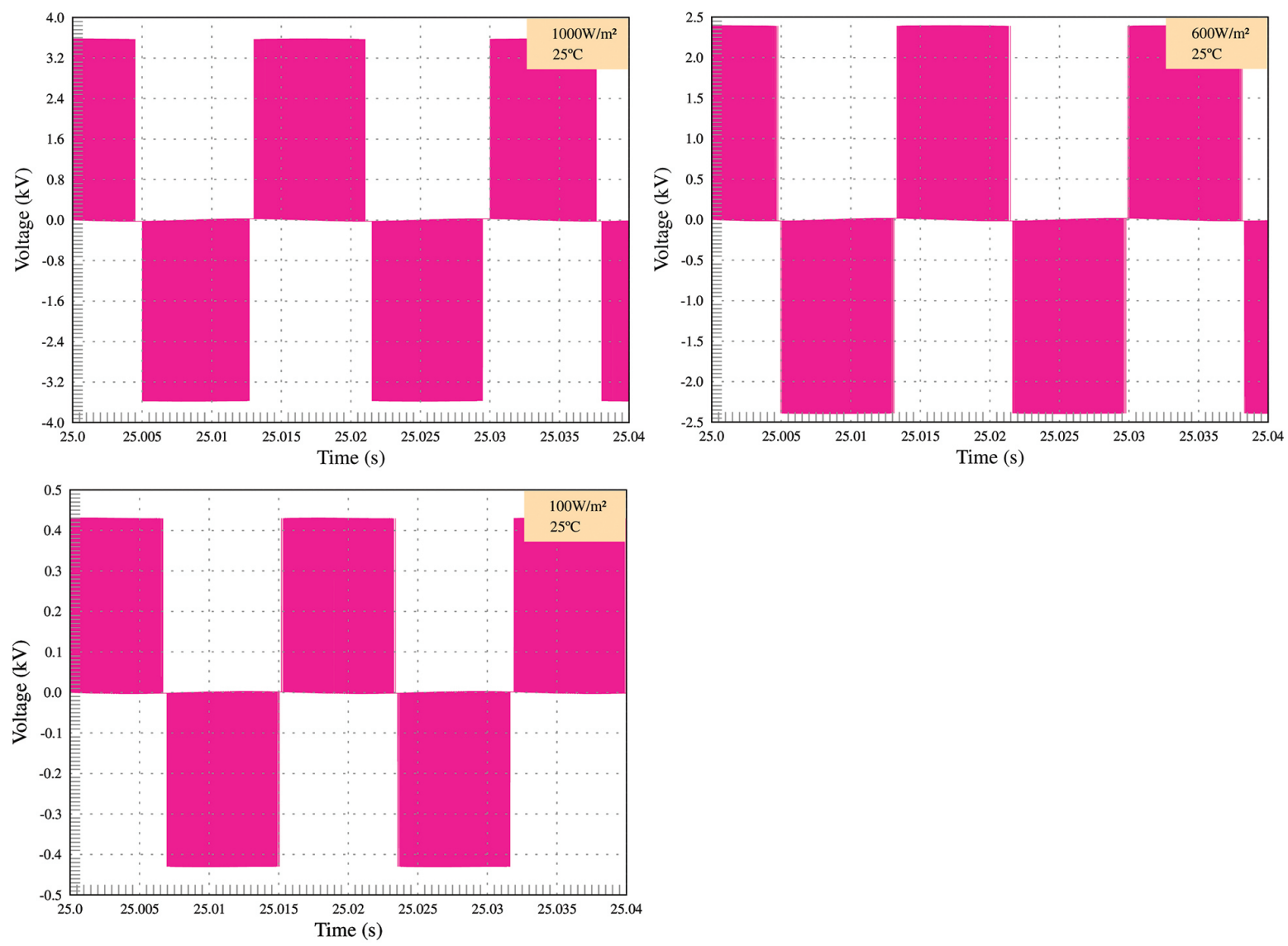

Fig. 28. $V_{\text {pwm }}$ response curves for solar irradiations of $1,000 \mathrm{~W} / \mathrm{m}^{2}, 600 \mathrm{~W} / \mathrm{m}^{2}$ and $100 \mathrm{~W} / \mathrm{m}^{2}$ at $25^{\circ} \mathrm{C}$. 


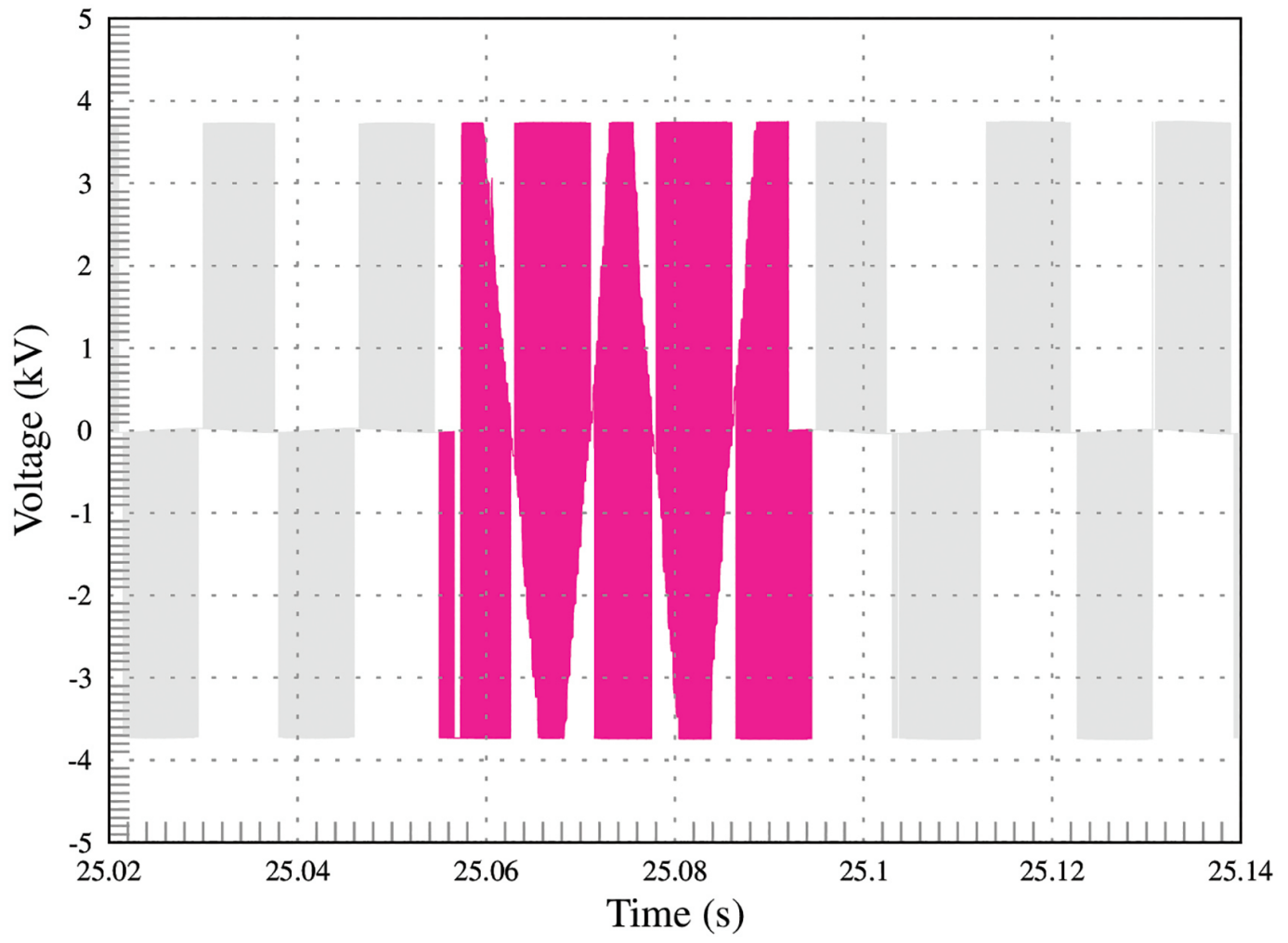

$\square$ GTO on

$\square$ GTO off

Fig. 29. GTO drive simulation. GTO, Gate Turn-Off Thyristor.

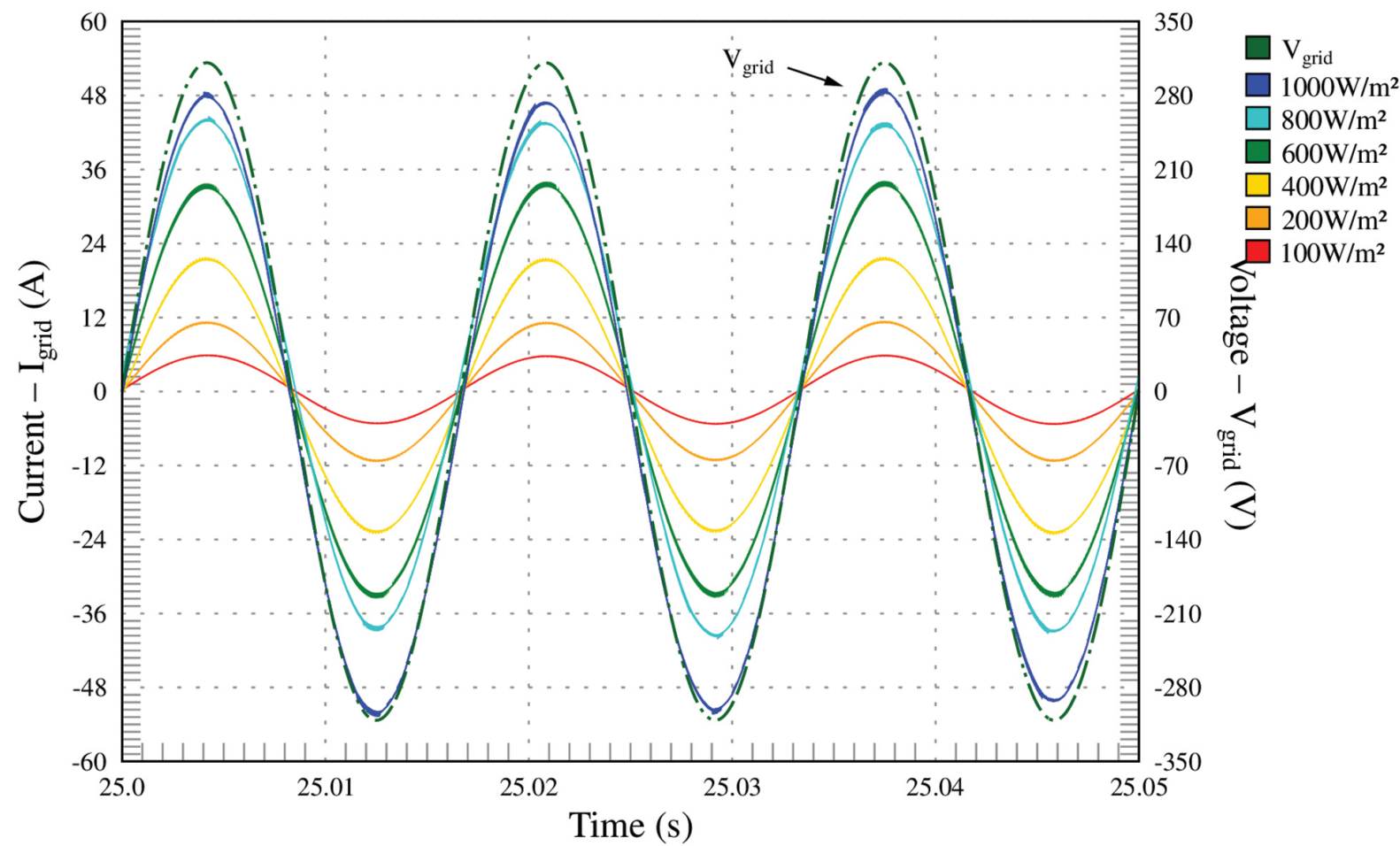

Fig. 30. $\mathrm{V}_{\text {grid }}$ and $\mathrm{I}_{\text {grid }}$ response curves for solar irradiances of $1,000 \mathrm{~W} / \mathrm{m}^{2}, 800 \mathrm{~W} / \mathrm{m}^{2}, 600 \mathrm{~W} / \mathrm{m}^{2}, 400 \mathrm{~W} / \mathrm{m}^{2}, 200 \mathrm{~W} / \mathrm{m}^{2}$ and $100 \mathrm{~W} / \mathrm{m}^{2}$ at $25^{\circ} \mathrm{C}$. 
$(19,200 \mathrm{~Hz})$, which allowed filtration with an efficient coupling inductor, causing $\mathrm{I}_{\text {grid }}$ currents to show low harmonic distortions at high frequencies $(>600 \mathrm{kHz}$ ) only. However, because of the choice of a high switching frequency of the transistors $(19,200 \mathrm{~Hz})$, there was a decrease in output efficiency of the DC/AC converter. This can easily be observed with the increased $I_{\text {grid }}$ current supplied by the DC/AC converter, as shown in Figure 25.

\section{Conclusions}

In this article, the investigation of a proposed control strategy for a single-phase DC/AC on-grid converter was designed and simulated with the PSCAD/EMTDC software. The implementation of the DC/DC conversion stage proved to be efficient and effective in stabilising the supply voltage to the DC/AC converter. In addition, the DC/DC stage was efficient to reach maximum power transfer through the incremental conductance algorithm for the I-V curve maximum power point tracking.

The DC/AC conversion stage showed low harmonic distortion and allowed a satisfactory DC/AC conversion rate compared to commercial converters. Already, the control system PLL based on the Park transformation allowed a dynamic and static control, acting in the angular displacement of the injected $I_{\text {grid }}$ current. Thus, obtaining a unit power factor and also acting in the amplitude modulation, allowing maximum power transfer in conjunction with the DC/DC converter, was made possible.

The simulations, graphs and mathematical equations presented prove the efficiency and effectiveness of the proposed strategy, which can serve as the basis for a more complete and even simpler control system for DC/AC converters used in photovoltaic systems. The simulation using discrete components allows the investigation of the responses at every stage of the circuit. Once optimised, the control strategy can be implemented through digital signal processing in the next project stage, which is the physical implementation of the circuit.

\section{Nomenclature}

\begin{tabular}{lll}
\hline Symbol & Description & Unit \\
\hline \hline$\theta$ & Phase angle & radian \\
$\Delta i_{L}$ & Variation of the output current through the output inductor & ampère \\
$\Delta l_{p v}$ & Variation of the photovoltaic current & ampère \\
$\Delta P_{p v}$ & Variation of the photovoltaic power & watt \\
$\Delta V_{p v}$ & Variation of the photovoltaic voltage & volt \\
$\Delta t$ & Variation of the time & second \\
$D C$ & Direct current & ampère \\
$C A$ or $A C$ & Alternating current & ampère \\
$D$ & Duty-cycle & percent \\
$d e n t V_{\text {grid }}$ & Reference AC voltage angle signal & radian \\
$d e n t I_{\text {grid }}$ & Reference AC current angle signal & radian \\
$D S P$ & Digital Signal Processor & - \\
$F P G A$ & Field Programmable Gate Array & - \\
$f_{\text {sin }}$ & Control signal frequency & hertz \\
$f_{t \text { tri }}$ & Carrier signal frequency & hertz \\
$G T O$ & Gate Turn-Off Thyristor & - \\
\hline & &
\end{tabular}




\begin{tabular}{|c|c|c|}
\hline Symbol & Description & Unit \\
\hline$l_{\rho v}$ & Photovoltaic current & ampère \\
\hline$l_{\text {grid }}$ & Alternating current from $A C$ power & ampère \\
\hline$I_{\text {rad }}$ & Solar Irradiance & watt/m2 \\
\hline$l_{\mathrm{sc}}$ & Short-circuit photovoltaic current & ampère \\
\hline L & Output Inductor & henry \\
\hline$m_{a}$ & Amplitude modulation rate & volt \\
\hline$m_{f}$ & Frequency modulation rate & volt \\
\hline Mppt & Signal maximum power point tracking & volt \\
\hline MPP & Maximum Power Point & - \\
\hline$N_{s}$ & Number of turns in a transformer secondary coil & - \\
\hline$P G$ & Phase Generator & - \\
\hline Pl & Proportional-integral & - \\
\hline PID & Proportional-integral derivative & - \\
\hline$P$ & Active power & watt \\
\hline$P L L$ & Phase-Locked Loop & - \\
\hline$P_{m p o}$ & Power in the maximum power point & watt \\
\hline$P_{\text {ref }}$ & Active power reference & watt \\
\hline PWM & Pulse Width Modulation & percent \\
\hline Q & Reactive power & volt-ampere reactive \\
\hline$Q_{\text {ref }}$ & Reference reactive power & volt-ampere reactive \\
\hline$R G$ & Reference Generator & - \\
\hline SPWM & Sinusoidal Pulse Width Modulation & percent \\
\hline SEC & Electrical System of Consumption & - \\
\hline SEP & Electric Power System & - \\
\hline$T_{e m p}$ & Temperature & degrees \\
\hline$V_{a b}=V_{p w m}$ & Voltage between $A-B$ points & volt \\
\hline$V_{d c}$ & Direct voltage & volt \\
\hline$V_{0}$ & Output voltage & volt \\
\hline$V_{o c}$ & Open-circuit photovoltaic voltage & volt \\
\hline$V_{p}$ & Transformer primary voltage & volt \\
\hline$V_{p v}$ & Photovoltaic voltage & volt \\
\hline$V_{s}$ & Transformer secondary voltage & volt \\
\hline$v_{m, \text { sin }}$ & Control signal voltage amplitude & volt \\
\hline$v_{m, t r i}$ & Carrier signal voltage amplitude & volt \\
\hline$V_{\text {grid }}$ & Alternating voltage from $A C$ power & volt \\
\hline$v_{\sin }$ & Control signal & volt \\
\hline$v_{t r i}$ & Carrier signal & volt \\
\hline$Z_{i n v}$ & Impedance output of inverter & ohm \\
\hline
\end{tabular}




\section{References}

Andish, M. M, Jalilzadeh, T., Alishah, R. S. and Sabahi, M. (2016). Leakage Current Elimination of Grid-Connected PV Panels Using an Improved Non-Isolated DC-AC Heric Converter. In The International Conference on New Researches in Engineering Sciences-RKES 2016, Tehran: University of Tehran.

Barbi, P. I. (2008). Projetos de Inversores. Edited by P. de P. em E. E. da UFSC. Santa Catarina.

Chettibi, N. and Mellit, A. (2014). Simulation Modelling Practice and Theory FPGA-Based Real Time Simulation and Control of Grid-Connected Photovoltaic Systems. Simulation Modelling Practice and Theory, 43, pp. 34-53. doi: 10.1016/j. simpat.2014.01.004.

Dousoky, G. M., Ahmed, E. M. and Shoyama, M. (2013). MPPT Schemes for Single-Stage ThreePhase Grid- Connected Photovoltaic VoltageSource Inverters. Proceedings of the IEEE International Conference on Industrial Technology, pp. 600-605. doi: 10.1109/ICIT.2013.6505739.

Eltawil, M. A. and Zhao, Z. (2013). MPPT Techniques for Photovoltaic Applications. Newable and Sustainable Energy Reviews, 25, pp. 793-813. doi: 10.1016/j.rser.2013.05.022.

Gajewski, P. and Pienkowski, K. (2016). Performance of Sensorless Control of Permanent Magnet Synchronous Generator in Wind Turbine System. Power Electronics and Drives, 1(2), pp. 165-174. doi: $10.5277 /$ ped160210.

Gerardo, V. G., Raymundo, M.-R. and Miguel, S. Z. (2015). High Efficiency Single-Phase TransformerLess Inverter for Photovoltaic Applications. Ingeniería, Investigación y Tecnología, 16(2), pp. 173-184. doi: 10.1016/j.riit.2015.03.002.

Guo, B., Su, M., Sun, Y., Wang, H., Dan, H., Tang, Z., Cheng, B. (2019) A Robust Second-Order Sliding Mode Control for Single-Phase Photovoltaic Grid-Connected Voltage Source Inverter. IEEE Access, 7, pp. 53202-53212. doi: 10.1109/ ACCESS.2019.2912033.

Hassaine, L. and Bengourina, M. R. (2020). Control Technique for Single Phase Inverter Photovoltaic System Connected to the Grid. Energy Reports, 6, pp. 200-208. doi: 10.1016/j.egyr.2019.10.038.

Hairi, M. H. (2019). Design and Modelling of a Three-Phase Grid-Connected Photovoltaic for Low Voltage Network using PSCAD Software. International Journal of Electrical Engineering and Applied Sciences, 2(1), pp. 1-6.
Hart, D. W. (2010). Power Electronics. New York: The McGraw-Hill Companies, Inc.

Jalilzadeh, T., Hagh, M. T. and Sabahi, M. (2018). Analytical Study and Simulation of a TransformerLess Photovoltaic Grid-Connected Inverter With a Delta-Type Tri-Direction Clamping Cell for Leakage Current Elimination. COMPEL-The International Journal for Computation and Mathematics in Electrical and Electronic Engineering.Vol. 37 Issue: 2, pp.814-831.

Johnson, B. A. (2013). Modeling and Analysis of a PV Grid-Tied Smart Inverter's Support Functions. CA: The Faculty of California State University.

Kwasny, L. and Zieliński, D. (2021). Control of a FourWire Hybrid Prosumer Converter for Balancing Utility Grids. Power Electronics and Drives, 6(1), pp. 1-11. doi: 10.2478/pead-2021-0001.

Luo, F. L. and Ye, H. (2017) Advanced DC/AC Inverters Applications in Renewable Energy. Edited by C. P. T. \& F. Group. Boca Raton: CRC Press. doi: 10.1201/b13750-8.

Manitoba HVDC Research Centre. (2018). Photovoltaic Example. Available at: https://www.pscad.com/ knowledge-base/article/176.

Massawe, H. B. (2013). Grid Connected Photovoltaic Systems with SmartGrid Functionality. Trondheim: Norwegian University of Science and Technology.

Monfared, M., Sanatkar, M. and Golestan, S. (2012). Direct Active and Reactive Power Control of Single-Phase Grid-Tie Converters. IET Power Electronics, 5(8), pp. 1544-1550. doi: 10.1049/ietpel.2012.0131.

Pinho, J. T. and Galdino, M. A. (2014). Manual de Engenharia para Sistemas Fotovoltaicos. Ediouro Gráfica e Editora. Available at: http://scholar.google. com/scholar?hl=en\&btnG=Search\&q=intitle:Manua I+de+engenharia+para+sistemas+fotovoltaicos\#0. [Accessed 5 Apr. 2021].

Rezk, H. and Eltamaly, A. M. (2015). A Comprehensive Comparison of Different MPPT Techniques for Photovoltaic Systems. Solar Energy, 112, pp. 1. doi: 10.1016/j.solener.2014.11.010.

Roomi, M. M. (2019). An Overview of Carrier-based Modulation Methods for Z-Source Inverter. Power Electronics and Drives, 4(1), pp. 15-31. doi: 10.2478/pead-2019-0007.

Salem, M. and Atia, Y. (2015). Control Scheme Toward Enhancing Power Quality and Operational Efficiency af Single-Phase Two-Stage Grid-Connected 
Photovoltaic Systems. Journal of Electrical Systems and Information Technology, 2(3), pp. 314-327. doi: 10.1016/j.jesit.2015.05.002.

Simões, M. G. and Farret, F. A. (2017). Modeling Power Electronics and Interfacing Energy Conversion Systems. New Jersey: John Wiley \& Sons.

Sundar, G., Karthick, N. and Reddy, S. R. (2014). High Step-Up DC-DC Converter for AC Photovoltaic Module with MPPT Control. Journal of Electrical Engineering, 65(4), pp. 248-253. doi: 10.2478/jee2014-0038.

Website - Canadian (inverter) (2021). Available at: https://www.canadiansolar.com/inverter/[Accessed 5 Apr. 2021].
Website - Canadiansolar (module) (2021). Available at: https://www.canadiansolar.com/bihiku/ [Accessed 5 Apr. 2021].

Website - Itron (2021) Available at: https://www. itron.com/br/solutions/product-catalog/ace6000 [Accessed 5 Apr. 2021].

Xiao, W. (2017). Photovoltaic Power System - Modeling, Design, and Control, Photovoltaic Power System. Edited by U. of Sydney. New Jersey: John Wiley \& Sons Ltd. doi: 10.1002/9781119280408.

Youssef, M., Boubahri, C., Fetni, S. and Aloui, F. (2020). Simulation and Design of a Single Phase Inverter with Digital PWM Issued by an Arduino board. ResearchGate. doi: 10.17577/IJERTV9IS080237. 